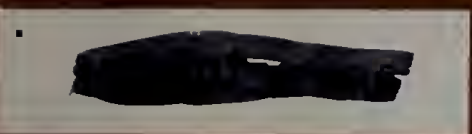

.456

80-2077

1 Y४U

$c .2$ 

'1.

\section{DEVELOPMENT OF RECOMMENDED}

TEST METHOD FOR TOXICOLOGICAL

ASSESSMENT OF INHALED COMBUSTION PRODUCTS

Merritt M. Birky, Maya Paabo, Barbara C. Levin,

Susan E. Womble, Dolores Malek

Center for Fire Research

National Engineering Laboratory

National Bureau of Standards

U.S. Department of Commerce

Washington, DC 20234

September 1980

Final Report

Prepared for:

Products Research Committee (PRC)

c/o Dr. John Lyons

National Bureau of Standards

Washington, DC 20234

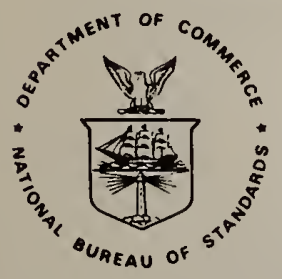

U.S. DEPARTMENT OF COMMERCE, Philip M. Klutznick, Secretary

Luther H. Hodges, Jr., Deputy Secretary

Jordan J. Baruch, Assistant Secretary for Productivity. Technology, and Innovation NATIONAL BUREAU OF STANDARDS, Ernest Ambler, Director 


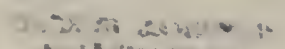

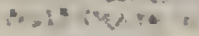
और 4 . 7 ?

- 
Page

LIST OF FIGURES . . . . . . . . . . . . . . . . . . . . . . iv

LIST OF TABLES . . . . . . . . . . . . . . . . . . . . . . v

Abstract . . . . . . . . . . . . . . . . . . . . 1

1. PROJECT DESCRIPTION . . . . . . . . . . . . . . . . . . 2

1.1 Scientific Background . . . . . . . . . . . . 2

1.2 Objective . . . . . . . . . . . . . . . . . . 2

1.3 Approach . . . . . . . . . . . . . . . . . . . . 2

1.4 Major Accomplishments . . . . . . . . . . . . . 3

2. ANIMAL EXPOSURE SYSTEM AND TEST METHOD . . . . . . . . . . . 4

3. MIXING CHARACTERISTICS OF THE EXPOSURE SYSTEM • • . . . . • . 4

3.1 Analytical Measurements . . . . . . . . . . . . . 4

3.2 Toxicological Measurements . . . . . . . . . . . 6

4. BLOOD CYANIDE MEASUREMENTS . . . . . . . . . . . . . . . . 6

4.1 Background . . . . . . . . . . . . . . . . . 6

4.2 Experimental Details.................. . . . . . 7

4.2.1 Conway Microdiffusion/GC-ECD Technique . . . . . 7

4.2.2 Head Gas/GC-NPD Technique . . . . . . . . . . 8

4.3 Animal Exposure to $\mathrm{HCN}$. . . . . . . . . . . . . . 8

5. EVALUATION OF TOXICITY OF VARIOUS MATERIALS . . • . . . • . . . 9

5.1 General Toxicological Information . . . . . . . . . 9

5.2 Toxicological Results ................. . 10

5.2 .1 Douglas Fir .................. . . . . 10

5.2 .2 Modacrylic ................... 11

5.2 .3 Wool ...................... . . . 11

5.2.4 Polytetrafluoroethylene (PTFE) . . . . . . . . 12

5.2.5 Flexible Polyurethane $(\mathrm{GM}-21)$. . . . . . . . 12

6. SUMMARY AND CONCLUSIONS . . . . . . . . . . . . . . . . 12

7. REFERENCES . . . . . . . . . . . . . . . . . 14

APPENDIX A. PROPOSED TEST METHOD FOR INTERLABORATORY

COMPARISON OF COMBUSTION PRODUCT TOXICITY . . . . . A-1 
Figure 1. Exposure chamber . . . . . . . . . . . . . . 15

Figure 2. Flow diagram of analytical systems for combustion products analysis... . . . . . . . . . . . 16

Figure 3. $\mathrm{CO}_{2}$ concentrations from $10 \mathrm{mg} / \mathrm{l}$ of Douglas fir . . . . 17

Figure 4. HCl profiles in the exposure box . . . . . . . . . . 18

Figure 5. HCN profiles in the exposure box . . . . . . . . . . . 19

Figure 6. Incapacitation of cannulated animals . . . . . . . . 20

Figure 7. Head space analysis of $\mathrm{HCN}$. . . . . . . . . . . . . 21

Figure 8. Solubility of $\mathrm{HCN}$ in water . . . . . . . . . . . . 22

Figure 9. Change in blood cyanide content during exposure to flaming modacrylic .. . . . . . . . . . . . 23

Figure 10. Restrainer for rats . . . . . . . . . . . . . . . 24

Figure 11. Atmospheric and blood levels of carbon monoxide at different mass loadings of Douglas fir decomposed by flaming combustion . . . . . . . . . . . . . 25

Figure 12. Atmospheric and blood levels of carbon monoxide and cyanide at different mass loadings of modacrylic decomposed by flaming combustion .. . . . . . . . 26

Figure 13. Atmospheric and blood levels of carbon monoxide and cyanide at different mass loadings of modacrylic decomposed in the non-flaming mode

Figure 14. Atmospheric and blood levels of carbon monoxide and cyanide at different mass loadings of wool decomposed in the flaming mode . . . . . . . . . 28

Figure 15. \& incapacitation and 8 death at different mass loadings of wool in the flaming mode .. . . . . . . 29

Figure 16. 8 incapacitation and $\%$ death at different mass loadings of wool in the non-flaming mode ....... . 30

Figure 17. PTFE - post exposure death . . . . . . . . . . . . 31

Figure 18. Post exposure mortality from non-flaming flexible polyurethane foam, $(\mathrm{GM}-2 \mathrm{l})$. . . . . . . . . . .

Figure 19. Toxicity $\left(\mathrm{EC}_{50}+\mathrm{LC}_{50}\right)$ of combustion products from PTFE, modacrylic, and wool decomposed in both flaming (F) and non-flaming (NF) modes as compared to that of Douglas fir . . . . . . . . . . . . . . . . 
Table 1. Data used in calculation of $(\mathrm{Chi})^{2}$ test of independence of order of incapacitation and animal position in flaming experiments... . . . . . . . 34

Table 2. Analytical methods for measuring blood cyanide . . . . . . 35

Table 3. Auto-ignition temperatures and temperatures used in the flaming and non-flaming modes . . . . . . . . 36

Table 4A. Summary of test method data . . . . . . . . . . . . 37

Table 4B. Summary of test method data . . . . . . . . . . . . . 38

Table 5. Control blood values . . . . . . . . . . . . . . 39

Table 6. Experimental temperatures of combustion and toxicity results . . . . . . . . . . . . . . . . . . . 40

Table 7. Analytical and blood data at $\mathrm{EC}_{50}$ and $\mathrm{LC}_{50} . . . . . .41$ 



\begin{abstract}
DEVELOPMENT OF RECOMMENDED TEST METHOD FOR TOXICOLOGICAL ASSESSMENT OF INHALED COMBUSTION PRODUCTS
\end{abstract}

Merritt M. Birky, Maya Paabo, Barbara C. Levin, Susan E. Womble, Dolores Malek

Abstract

The objective of the project supported by PRC was to develop a test method for measuring the toxicity of combustion products from polymeric materials including cellular plastics. The development of such a test procedure was considered an essential first step to determine the hazard to life when cellular plastics are involved in fire.

As a result of this work, a test procedure was developed. It consists of 3 major elements; (1) combustion system, (2) chemical analysis system and (3) animal exposure system. Two biological endpoints obtained from the exposure are: (1) incapacitation in 30 minute exposure period, and (2) lethality in 30 minutes plus 14 days post exposure.

The test apparatus has been evaluated to determine mixing rates and loss of reactive chemicals in the exposure chamber. In addition, a statistical evaluation of the experimental results demonstrated that order of incapacitation was independent of animal location.

Evaluation of a limited number of different materials that produce different toxicological syndromes has demonstrated the utility of all 3 endpoints. Two natural polymers (wood and wool) and 2 synthetic materials (modacrylic and PTFE) have been studied in detail. In addition, preliminary data have been obtained on a flexible polyurethane foam $(\mathrm{GM}-21)$.

Key words: Combustion; fatality $\left(L_{50}\right)$; hydrogen cyanide; incapacitation; inhalation; test method; toxicology. 


\section{PROJECT DESCRIPTION}

\subsection{Scientific Background}

Fire statistics show that approximately $70 \%$ of the fire fatalities in the U.S.A. are attributed to smoke inhalation. An extensive review of the scientific literative on the toxicity of combustion products [1] showed that a great deal of effort had been expended in trying to determine the toxic hazard associated with fires and to correlate this hazard with the chemical analysis of pyrolysis products. In the review, it was pointed out that the conclusion reached by those authors who conducted such analytical measurements was that more measurements were required before one could establish the toxicity of these products.

As a result of this information and experience in the field, it became apparent that if progress is to be made in our understanding of the toxicity of fire products, a judicious combination of chemical analysis and exposure of living organisms is required. Living organisms are required to determine the integrative effects of the large number of chemical species produced from a single polymeric material when it undergoes thermal decomposition. Furthermore, the evaluation of this complex mixture is complicated by the fact that various toxic products affect living organisms in different ways and in many cases these effects are unknown. Chemical analysis of selected toxic products is considered important to further our understanding of the toxic syndrome identified through the use of living organisms.

\subsection{Objective}

The objective of this study was to develop the measurement tools, in this case, a standardized procedure, by which the toxicity of combustion products could be measured. While the PRC program was limited to cellular plastics, our objective was to develop the basis for a toxicity protocol which was not limited to cellular plastics, but included all polymeric materials, both natural and synthetic.

\subsection{Approach}

The details of the test method are provided in Appendix A. In summary, the method consists of exposing 6 adult male rats in the head-only mode for a period of 30 minutes. The combustion products are generated in a cup furnace in the flaming and non-flaming modes in the bottom of a nominal 200 liter exposure chamber. Incapacitation, as defined by the hind-leg flexion behavioral model, and percent lethality, including deaths during the 30 minute exposure period and for a 14 day post-exposure period, are determined as a function of mass loading from which the LC $_{50}$ value is statistically determined. Blood carboxyhemoglobin saturation 50 sociated with the exposure is measured. Rats were chosen as the animal species rather than mice to provide a sufficient blood supply for COHb determinations as well as other selected blood parameters.

1 Numbers in brackets refer to the literature references listed at the end of this report. 
Heat stress and oxygen deprivation are eliminated as toxicological factors by chamber temperature and oxygen concentration control in order to reduce the scope of the problem to a manageable size. In addition, the static mode of exposure was chosen to reduce the preferential loss of low vapor pressure toxic species when transporting these species from the combustion chamber to the exposure chamber.

Combustion of the material in the exposure chamber was considered the most ideal solution as long as the environmental temperature was controlled to eliminate heat stress on the animals.

It was further decided that incapacitation should be an endpoint as well as death. Incapacitation was considered important since one would like an early indication that the combustion products are causing a toxicological problem and since investigations of fire fatalities indicated that in many cases the fire victims had made an attempt to escape. Since no incapacitation model appears to be universally responsive to the effects of all toxic chemicals, death was considered an important endpoint as well.

After due consideration of the above factors, a test apparatus and method were proposed. A copy of the proposed test method is attached as appendix A.

\subsection{Major Accomplishments}

During the period of PRC support, the following accomplishments have been realized:

(1) the development of an animal exposure system for use in the proposed test procedure,

(2) the determinations of the mixing characteristics of the system, both analytically and toxicologically,

(3) the development of a reliable analytical technique for hydrogen cyanide in the fire gases,

(4) the development of a more rapid technique for the measurement of blood cyanide and

(5) the determinations of the toxicity of the combustion products of samples of Dcuglas fir, wool: modacrylic, polytetrafluoroethylene and a flexible polyurethane.

The above accomplishments will be reviewed in detail in the following discussion. However, it should be noted that this is a progress report toward the development of a toxicity protocol and not a completed study. For example, while time to incapacitation is required in the proposed test method, time is not reported in this study pending further research on time effects versus concentration effects. Incapacitation is reported on a mass loading basis similar to the lethality end-point. 


\section{ANIMAL EXPOSURE SYSTEM AND TEST METHOD}

The animal exposure system is shown diagrammatically in figure 1. The chamber is constructed of $1.25 \mathrm{~cm}$ (1/2 in) polymethylmethacrylate (PMMA) and measures $122 \mathrm{~cm}$ (48 in) long by $46 \mathrm{~cm}$ (18 in) high by $36 \mathrm{~cm}$ (14 in) deep in inside dimensions. This chamber provides a nominal volume of 200 liters. Combustion products are generated in a small cup furnace inserted in the bottom of the chamber at the left end as noted in figure 1 . The furnace is of the design reported by Potts and Lederer [2]. For this test system, mass loading of combustion products is defined as the weight of the material added to the furnace in milligrams divided by the volume of the exposure chamber. in liters $(\mathrm{mg} / \mathrm{l})$.

Various radiant heat systems were tried without success. The major difficulty was designing a system that was compatible with the animals, that is, all systems tested produced an unacceptable temperature rise in the exposure chamber. The first system that was tested was a radiant panel (quartz-iodide lamps) that was placed outside the chamber and the radiation was directed through a quartz window.

A second radiant system was placed inside the chamber where the top of the furnace is located. This system consisted of a truncated pyrex cone coated with a reflective layer and wrapped with a resistance coil on the inside surface of the cone.

Again, the heat losses were large enough that the chamber temperature rose beyond the $35^{\circ} \mathrm{C}$ environmental temperature limit specified in the proposed test method.

The proposed test method, a description of which is attached as Appendix A, details the apparatus and procedure that was used for the combustion product toxicity determinations. The method may undergo further modifications as more materials are evaluated and as the results of an interlabcratory evaluation of the method by nine laboratories are analyzed.

The gas analysis system for $\mathrm{CO}, \mathrm{CO}_{2}$ and $\mathrm{O}_{2}$ is shown by figure 2. The $\mathrm{CO}$ and $\mathrm{CO}_{2}$ are measured by continuous flow commercial infrared analyzers. The $\mathrm{O}_{2}$ is determined by a galvanic cell. These gas concentrations are measured continuously and since these are routine measurement techniques, they will not be described further except to note that the $0.5 \mathrm{l} / \mathrm{min}$. gas stream used for this analysis is returned to the exposure chamber.

\section{MIXING CHARACTERISTICS OF THE EXPOSURE SYSTEM}

\subsection{Analytical Measurements}

Prior to the exposure of animals in the proposed test method, extensive analytical measurements were made in the chamber at various locations to determine the mixing characteristics of the system. As noted in figure 1 , $\mathrm{CO}_{2}, \mathrm{HCl}$ and $\mathrm{HCN}$ determinations were made at three elevations (5 $\mathrm{cm}$ from top

2 Note: Certain commercial equipment, instruments, or materials are identified in this paper in order to adequately specify the experimental procedure. In no case does such identification imply recommendation or endorsement by the National Bureau of Standards, nor does it imply that the material or equipment identified is necessarily the best available for the purpose. 
and bottom and at center) along the front face of the chamber in a vertical line between animal ports 3 and 4 . In addition, an HCN measurement was made $5 \mathrm{~cm}$ from the bottom of the chamber at the far end.

The results of the $\mathrm{CO}_{2}$ measurements taken when $10 \mathrm{mg} / \mathrm{l}$ of Douglas fir was thermaliy degraded at $240^{\circ} \mathrm{C}$ (non-flaming) are shown in figure 3. For this analysis, samples were collected in pre-evacuated bulbs and analyzed gas chromatographically.

As indicated in figure 3 , mixing occurs very rapidly in the chamber and there were no significant gradients between the three levels under the test conditions. Similar results were obtained with 20 and $30 \mathrm{mg} / \mathrm{l}$ samples.

Repeated combustion of wood samples at a fixed loading was carried out to determine the repeatability of the system. In this case, carbon monoxide was measured in addition to $\mathrm{CO}_{2}$ and reproducible results were obtained. Continued measurements of $\mathrm{CO}$ from other materials have confirmed this finding.

A poly (vinylchloride) was degraded at $475^{\circ} \mathrm{C}$ in the non-flaming mode to generate $\mathrm{HCl}$ in the exposure chamber. These measurements were designed to determine if concentration gradients existed in the system when a reactive gas such as HCl was present and to establish the adsorptivity of $\mathrm{HCl}$ on the PMMA used for construction of the exposure chamber.

The $\mathrm{HCl}$ analysis was made with an ion selective electrode. The technique for trapping the gaseous $\mathrm{HCl}$ was similar to that described by O'Mara [3]. $10 \mathrm{ml}$ disposable plastic syringes were used to withdraw $5 \mathrm{ml}$ gas samples simultaneously at the three sampling ports. Once the gas was in the syringe, $5 \mathrm{ml}$ of $10^{-4} \mathrm{M}$ HCl solution was drawn into the syringe and the syringe was vigorously shaken. The scrubbing was repeated three more times.

The dissolved $\mathrm{HCl}$ was measured with a chloride ion-selective electrode (Orion 92-17A) 2 in conjunction with a double junction reference electrode (Orion 90-02). Emf measurements were made with a digital pH meter that had been calibrated with standard $\mathrm{HCl}$ solutions in the range of $10^{-2}$ to $5 \times 10^{-5} \mathrm{M}$. The concentration of $\mathrm{HCl}$ in the gaseous samples was calculated using calibration curves obtained by plotting electrode potentials versus the log of $\mathrm{HCl}$ concentrations.

The efficiency of the syringe sampling technique was checked by comparing it with a standard sampling procedure employing midget impingers and a large volume of gas. Two liters of HC.l reference gas $(4000 \mathrm{ppm})$ were collected in two impingers filled with $15 \mathrm{ml}$ of $28 \mathrm{NaOH}$. After sampling, the chloride content of the combined trapping solution was measured with the ion-selective electrode. The efficiency of the syringe sampling technique was found to be $82 \pm 2 \%$.

The results of two $\mathrm{HCl}$ measurements in the test chamber are illustrated in figure 4. The broken line is the theoretical quantity of HCl based on formulation information. In the first experiment, the HCl concentration was lower in the upper position than in the lower two, unlike the second experiment where the concentration was the same in all three positions. There was some evidence of inhomogeneity as the initial $\mathrm{HCl}$ concentration in the second experiment was above the theoretical amount (based on $92 \%$ resin content). As evidenced by the rate of decrease in $\mathrm{HCl}$ concentration and comparison with theoretical yield, adsorption does not appear to be unreasonably large suggesting that this chamber is suitable for the exposure system.

As noted in figure 1, cyanide determinations were also made at three levels. In this case various nitrogen containing polymers were used. The results of measurements when wool was thermally degraded at $625^{\circ} \mathrm{C}$ (nonflaming) are shown in figure 5. In this figure, two separate determinations 
at different mass loadings (sample weight in furnace) are illustrated. As noted in this figure, there was no significant stratification of $\mathrm{HCN}$ in the box and mixing was good within the 1.0 minute-sampling period.

The analytical procedure for the HCN determinations was based on a gas chromatographic technique utilizing a nitrogen specific detector. The details of this technique have been published [4].

These measurements on $\mathrm{CO}_{2}, \mathrm{HCl}$ and $\mathrm{HCN}$, although limited, show that mixing in the chamber is rapia' compared to the 30 minute exposure period and that stratification and absorption do not appear to be problems, at least for these products. One would expect that other products would have behave similarly and that there would not be concentration gradients. This has been proven by subsequent toxicity studies detailed in the following section.

\subsection{Toxicological Measurements}

To demonstrate the overall adequacy of mixing in the inhalation chamber, a statistical aralysis [(Chi) test of independence] of both flaming and nonflaming experiments was made to determine if the time order of incapacitation was independent of animal location. Table 1 shows the data used to calculate the (Chi) test of independence of the order of incapacitation and animal position in 45 flaming experiments. Flaming data were analyzed separately from non-flaming to determine if radiation effects (heat stress) were having an effect on the animals in addition to possible concentration gradients.

This analysis of the data showed that the order of incapacitation was statistically independent of the animal position in both the flaming and non-flaming experiments. The experimental variation noted was not significant at the $p=0.05$ level.

However, the statistical analysis did show that cannulated animals do have a tendency to be incapacitated first. This is shown by figure 6 . Two animals out of six used in each experiment were cannulated. If the cannulated animals had an equal probability of being incapacitated first, the data would show that $33 \%$ of the time a cannulated animal would be first as shown by the solid line in the bar graph. However, a cannulated animal was incapacitated first $74 \%$ of the time. This analysis shows that the cannulated animals are slightly more susceptible to the effects of toxic products.

More importantly, the statistical analysis of the data shows that within the limits of the data, all six positions are equivalent. These findings confirm the extensive analytical data.

\section{BLOOD CYANIDE MEASUREMENTS}

\subsection{Background}

Past efforts to evaluate the toxicological importance of $\mathrm{HCN}$ in the fire environment had been handicapped by the lack of a rapid and accurate technique for determination of cyanide in blood. Several methods are available for blood cyanide and these our outlined in table 2. They all require relatively large volumes of blood (several milliliters) for the isolation step which itself is time consuming (2-3 hours). In these methods, the cyanide is separated from blood and analyzed by a number of techniques.

In the course of exposure of animals to degradation products of modacrylic, two methods were used for determining blood cyanide. First, in the non-flaming modacrylic exposures, blood cyanide was determined by a modification of a gas chromatographic method of Valentour [5]. In this case the 
cyanide was isolated from the blood utilizing the micro-diffusion technique of Feldstein and Klendshoj [6].

This multistep process uses Conway microdiffusion dishes for isolation of volatile HCN. The cyanide is converted to cyanogen chloride with chloramine-T, extracted with $n$-hexane and detected by gas chromatography using an electron capture detector. In addition to the time required for carrying out the procedures, the main disadvantage of this technique is that only one blood cyanide determination can be made per animal.

In combustion toxicity studies, it is desirable to take repeated blood samples during an exposure in order to determine blood cyanide content at the time of incapacitation as well as at the time of death. This requires a rapid and simple blood cyanide analysis method using small volumes of blood. Such a method was developed based on the analysis of head gas above an acidified blood sample. This second technique was used for flaming modacrylic studies.

This technique involves isolation of $\mathrm{HCN}$ by acidification of a small blood sample $(0.2 \mathrm{ml})$ in a gas tight container, followed by analysis of $\mathrm{HCN}$ in the head gas by the same gas chromatographic technique as used for environmental HCN.

\subsection{Experimental Details}

\subsubsection{Conway Microdiffusion/GC-ECD Technique}

Two ml of $0.1 \mathrm{~N} \mathrm{NaOH}$ is added to the inner wall of a Conway microdiffusion dish. A $2 \mathrm{ml}$ aliquot of the blood sample is placed into the outer chamber to which $2 \mathrm{ml}$ of $1 \mathrm{~N}$ tartaric acid is added. The dish is immediately sealed with a glass cover. The acid and blood are mixed with gentle swirling and allowed to stand at room temperature for 2 hours. The alkaline NaCN solution is pipetted from the center well and subjected to wet chemistry for converting the cyanide to cyanogen chloride.

To $1 \mathrm{ml}$ of $\mathrm{NaCN}$ solution in a septum sealed vial, $2 \mathrm{ml}$ of $\mathrm{n}$-hexane, $1 \mathrm{ml}$ of $1 \mathrm{M} \mathrm{NaH} \mathrm{PO}_{4}$, and $1 \mathrm{ml}$ of chloramine $\mathrm{T}$ solution (0.26\%) are added. The vial is shaken for 30 seconds and allowed to stand for 5 minutes for the n-hexane layer to separate. All reagents and the reacting mixture are cooled in an ice bath.

The HCN (in the form of cyanogen chloride in the hexane layer) was quantified by gas chromatography. A gas chromatogram equipped with a ${ }^{3} \mathrm{Ni}$ pulsed linearized electron capture detector was used for this purpose. 1 ul samples of the hexane layer were injected on to a $6 \mathrm{ft}$. $x 1 / 4$ in. O.D. stainless steel column packed with 78 Halcomid M-18 on Anakrom ABS, $190-100$ mesh). The column was operated isothermally either at 75 or $85^{\circ} \mathrm{C}$. The injection port was at $150^{\circ} \mathrm{C}$ and the detector was kept at $300^{\circ} \mathrm{C}$. Five percent methane in 958 argon was used as a carrier gas at a flow rate of 60 $\mathrm{ml} / \mathrm{min}$. Chromatograms were traced with a recorder and the peak areas determined with a digital integrator. The GC system was calibrated with standard aqueous cyanide solutions
$(0.1-10 \mathrm{ug} / \mathrm{ml})$ which were subject to similar wet chemical conversion steps. The first n-hexane solvent peak was used as an internal standard and the ratio of the peak heights of cyanogen chloride to n-hexane was related to HCN concentration in blood using a standard $\mathrm{KCN}$ solution of similar concentration.

The efficiency of the microdiffusion step was evaluated by spiking blood samples with KCN solutions in the range of 0.1 to $5 \mathrm{ug} / \mathrm{ml}$ and subjecting the samples to blood cyanide analysis procedure. Standard curves 
were calculated based on the detector response to aqueous reference solutions containing $\mathrm{KCN}$. Spiked blood analyzed by microdiffusion technique gave results lower than the theoretical amount. The average recovery efficiency of the Conway microdiffusion technique was found to be $73.1 \%$ with std. dev. \pm 6.3 . Blood cyanide values for exposed animals were corrected for this rēcovery efficiency.

\subsubsection{Head Gas/GC-NPD Technique}

In this technique, $0.2 \mathrm{ml}$ of blood is added to a $3 \mathrm{ml}$ vacutainer containing $0.2 \mathrm{ml}$ of $85 \% \mathrm{H}_{3} \mathrm{PO}$, mixed with a vortex mixer, and equilibrated for 1 hour in a waterbath at $60^{\circ} \mathrm{C}$. The HCN in the head gas was sampled with a 100 ul gas-tight syringe and quantified by gas chromatography using an alkali flame detector. The experimental parameters were the same as used for the analysis of environmental $\mathrm{HCN}$ in gaseous degradation products [4].

The efficiency of liberation of $\mathrm{HCN}$ from blood matrix under the experimental conditions was examined by comparing $\mathrm{HCN}$ concentrations in the head space of acidified $0.1 \mathrm{~N} \mathrm{NaOH}$ solutions and blood samples, both spiked with $\mathrm{CN}^{-}$in the range of $1-10 \mathrm{ug} / \mathrm{ml}$. A linear relationship was obtained between alkali flame detector response and cyanide concentration in the solutions for both substrates, as shown by figure 7. Repeatability of duplicate analysis was better than $\pm 6 \%$. Lower detection limit was estimated to be about $0.2 \mathrm{ug} \mathrm{cN} / \mathrm{ml}$. The portion of $\mathrm{HCN}$ liberated into the head space was $12.5 \%$ (std. dev. $\pm 0.8 \%$ ) for aqueous solutions and $9.4 \%$ (std. dev. $\pm 1.3 \%$ ) for blood samples.

The recovery of $\mathrm{HCN}$ from blood by the head gas technique was $75 \%$ of that from aqueous media. However, to avoid the uncertainty of this correction factor, spiked blood containing 10-20\% $\mathrm{H}_{2} \mathrm{O}$ was used for standardization purposes when cyanide levels were determined in blood of exposed animals.

The results of the head gas measurements permit the calculation of the partition ratio between $\mathrm{HCN}$ in the vapor phase and $\mathrm{HCN}$ in water and blood at $60^{\circ} \mathrm{C}$. The partition ratio is expressed as:

$$
1=\underline{\mathrm{mg} H \mathrm{HCN} / 1 \text { solution }}
$$

$\mathrm{mg} \mathrm{HCN} / 1$ gas

and was approximately 125 for water and 160 for blood. These results are compared with solubility data obtained from the literature for HCN in water (see figure 8 ) over a range of temperatures.

\subsection{Animal Exposure to $\mathrm{HCN}$}

The two techniques (head space and microdiffusion) described in the previous sections were used for determination of blood cyanide during exposure of animals to degradation products of modacrylic. The product load was varied between $2-5 \mathrm{mg} / \mathrm{l}$ which resulted in a concentration of $\mathrm{HCN}$ in the range of 100-275 ppm.

During non-flaming modacrylic experiments, the animals were sacrificed at the end of 30 minute exposure and blood samples were taken for cyanide determinations via the conway diffusion technique. The average blood-cyanide values ranged from 0.62 to $2.73 \mathrm{ug} / \mathrm{ml}$. The average deviation for five measurements with duplicate determinations was $\pm 8.5 \%$.

During flaming modacrylic experiments, the blood for cyanide determinations by the head gas technique was withdrawn from the cannula close to the time of incapacitation and near the end of the 30 minute exposure. The average blood cyanide levels varied between 1.91 and $6.53 \mathrm{ug} / \mathrm{ml}$. The reproducibility of the head gas technique was not as good as for the conway diffu- 
sion method. The average deviation for 10 blood samples with duplicate determinations was $\pm 21 \%$. Results of blood-cyanide concentrations as a function of exposure time are shown in figure 9. In this figure, the arrows indicate time of incapacitation.

The toxicological interpretation of blood cyanide findings will be discussed in section 5.2 .2 .

\section{EVALUATION OF TOXICITY OF VARIOUS MATERIALS}

\subsection{General Toxicological Information}

As indicated earlier, toxicological and analytical data have been obtained for Douglas fir, wool, modacrylic and PTFE using the proposed test procedure. Douglas fir was obtained as rectangular sheets approximately $30 \mathrm{~cm} \times 23 \mathrm{~cm} \times 1.9 \mathrm{~cm}$ and was cut into a cube of desired weight before each experiment. Wool was obtained as a roll of washed, unbleached and unwoven fibers. Modacrylic was a knit fabric. Both wool and modacrylic were cut into a piece of desired weight before each experiment. PTFE, a powder, was weighed on an analytical balance to insure precise weighing of the small quantities needed. Preliminary data have also been obtained for a flexible polyurethane foam $(\mathrm{GM}-21)^{3}$. The temperatures at which these data have been obtained are tabulated in table 3 . Polystyrene (GM-51) ${ }^{3}$ is listed in this table, but no toxicological data are reported here.

As specified in the test procedure, the animals are exposed head only. The restrainer tube used to hold the animals is illustrated in figure 10. These restrainers position the animals in the exposure chamber at the ports shown in figure 1. The details of the test procedure are given in appendix A.

Fisher 344 albino male rats were obtained weekly. The animals weighed 224-250 grams upon arrival and were kept at least 10 days before experiments in order to acclimate to our laboratory conditions of $22^{\circ} \mathrm{C}$ and $50 \%$ relative humidity. They were weighed during the laboratory acclimation period to assure normal weight gain.

Each arrival of animals was divided into experimental and control groups, i.e., a usual weekly arrival consisted of 28 animals, 24 were used for experiments ( 4 experiments, 6 animals each) and 4 were kept as controls. All animals were housed individually in suspended stainless steel wire cages in a temperature and humidity controlled room. Twelve hours of fluorescent lighting per day were controlled by an automatic timer. Food and water were consumed ad libitum. Fresh bedding was provided three times a week. All animals surviving exposure were kept 14 days and weighed 5 days per week.

The types of data that are recorded during the experiments are shown in tables $4 \mathrm{a}$ and $4 \mathrm{~b}$. These tables provide for the tabulation of all data except the concentration of various gases in the exposure chamber.

Blood measurements are performed on two of the six exposed animals. These two animals are cannulated at least 12 hours prior to the experiment. The cannula, which is placed in the left femoral artery, allows arterial blood to be drawn before, during (at 15 minutes and at incapacitation), and just prior to the end of the exposure.

3 Standard reference materials available from PRC. 
Nine different blood parameters are analyzed. Total hemoglobin (THb), carboxyhemoglobin (COHb), oxyhemoglobin $(\mathrm{O}, \mathrm{Hb})$, methemoglobin (MetHb) and volume of oxygen are measured by a co-oximeter which was calibrated for rat blood. The $\mathrm{pH}, \mathrm{pCO}_{2}$ and $\mathrm{pO}$, were measured on a blood gas analyzer. This instrument was calibrated before each experiment with a certified calibration standard clinical blood mixture made for in vitro diagnostic use. In addition, blood cyanide was measured by the procedures described in sections 4.2 and 4.3 .

At the beginning of an experiment before the sample is introduced into the furnace, arterial blood samples are taken from the two cannulated animals for control values. The control values for various arterial blood parameters are tabulated in table 5 and compared with similar values obtained at the University of Utah.

The major differences in the control values between the two laboratories are partial pressures of $\mathrm{CO}_{2}$ and $\mathrm{O}_{2}$. The Utah values are lower due to a difference in atmospheric pressure, as Salt Lake City is situated at an elevation approximately $5000 \mathrm{ft}$. and Washington is approximately at sea level.

\subsection{Toxicolgical Results}

The results of the toxicity measurements for the four materials that have been evaluated under conditions of non-flaming and flaming combustion are summarized in table 6. The temperature at which the material is degraded is listed in column 2 of the table. The third column $\left(\mathrm{EC}_{50}\right)$ is the mass loading of combustion products per unit volume required to cause incapacitation of $50 \%$ of the animals within the 30-minute exposure period. The 5 th and 4 th columns lists the mass loading that leads to lethality of $50 \%$ of the aninals $\left(\mathrm{LC}_{50}\right)$ in 30 minutes and 30 minutes plus 14 days post exposure, respectively. "While the residue in the furnace is determined by weighing, it is not taken into account for calculating the mass loading. The results of measurements on each of these materials will be discussed individually below.

\subsubsection{Douglas Fir}

A graph of the carbon monoxide concentrations and the resulting carboxyhemoglobin values versus different mass loading of Douglas fir tested in flaming mode are shown in figure 1l. The mass loading for $\mathrm{EC}_{50}$ and $\mathrm{LC}_{50}$ are overlayed as vertical lines on the figure. The carbon monoxide values are the average concentrations for the 30-minute exposure period.

Animals exposed to the flaming combustion of Douglas fir showed very high levels of carboxyhemoglobin (COHb). In figures $11-14, \mathrm{COHb}$ levels are indicated by circles; open circles mean that the animal died during the 30-minute exposure. Other blood parameters besides COHb values changed during the exposure. For example, the $\mathrm{O}_{2} \mathrm{Hb}$ and partial pressure of oxygen (p0 ${ }_{2}$ ) declined as the $\mathrm{COHb}$ increased. In adation, the partial pressure of $\mathrm{CO}_{2}\left(\mathrm{pCO}_{2}\right)$ increased and pH decreased as a result. All of the above blood parameters are for arterial blood.

From figure 11, one notes that for a 30-minute exposure, the $\mathrm{EC}_{5}$ occurred when there was about $1800 \mathrm{ppm}$ of $\mathrm{CO}$ and an average coHb concentration of 758 . For the $\mathrm{LC}_{50}$, the average COHb value was about $85 \%$. This data plus the finding that there were no post-exposure deaths indicates that the predominate cause of incapacitation and death from exposure to the flaming combustion products of Douglas fir is most likely carbon monoxide.

Results of non-flaming experiments with Douglas fir are shown in tables 6 and 7. As noted in these tables, the flaming mode is less toxic with all deaths attributed to $\mathrm{CO}$. 


\subsubsection{Modacrylic}

Analysis of the analytical and toxicological data for flaming and nonflaming combustion of the modacrylic fabric tested is shown in figures 12 and 13, respectively. In these figures, hydrogen cyanide environmental levels and blood cyanide are also recorded.

It is obvious, from environmental $\mathrm{CO}$ and $\mathrm{COHb}$ concentrations, that carbon monoxide is not a very significant toxicant in the cause of the incapacitation or death of the animals exposed to modacrylic decompositions. For example, $\mathrm{COHb}$ never exceeded $25 \%$ saturation. However, in the flaming mode, (figure 12, table 7) the average HCN concentration at the calculated EC Fo $_{\text {is }}$ about $125 \mathrm{ppm}$ and the corresponding average blood level is about $2.5 \mathrm{ug} / \mathrm{m}$. The average concentration of HCN for the calculated 30 -minute $\mathrm{LC}_{5}$ level is about $215 \mathrm{ppm}$ with a corresponding blood level of $4 \mathrm{ug} / \mathrm{ml}$. Under non-flaming conditions (figure 13, table 7), the environmental HCN concentrations at the $\mathrm{EC}_{50}$ and LC 50 were similar to those values found under flaming conditions. However, the blood cyanide levels found in the non-flaming mode were approximately half those found in the flaming mode. This apparent discrepancy may be due to analytical uncertainties in the blood cyanide measurements or to an increased toxicity from different combustion products produced in the non-flaming mode.

The presence of cyanide in the blood is indicative of exposure to atmospheric cyanide, however, the precise blood level may not reflect the magnitude of the exposure or the extent of the toxicological problem. The reason for this is found in the mechanism of cyanide toxicity.

First of all, cyanide is not toxic while in the blood. Cyanide toxicity results from interfering with the electron transport system within the cells of the tissues. It does not prevent the oxygenation of hemoglobin nor does it interfere with the metabolism of the red blood cells. Therefore, if cyanide is kept in the blood, it is essentially in a non-toxic state. In fact, cyanide can be kept in the blood by changing the Fe oxidation state

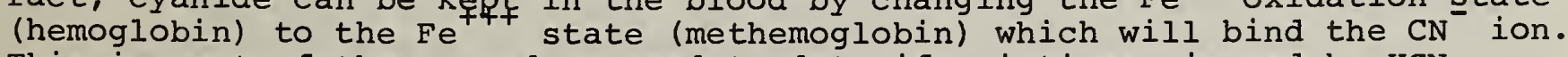
This is part of the procedure used to detoxify victims poisoned by $\mathrm{HCN}$.

It should be clear from the above that it is the total body burden resulting in a given tissue level which accounts for the toxicity of cyanide. Furthermore, this distribution is time dependent. That is, a low environmental concentration will provide more time for HCN to be distributed throughout the body fluids and to tissues, resulting in a lower blood level at incapacitation or death. A higher environmental concentration will saturate both the blood and the tissues rapidly, thus resulting in a higher value at incapacitation or death. Reference to the data shown in figure 9 suggest that bleod cyanide measurements are insufficient to demonstrate a causal relationship between death and inhaled cyanide. This suggests that using blood cyanide levels to determine cause of death in fire victims may be misleading. Experiments on pure cyanide and its distribution between the blood and other body tissues may help to resolve this problem.

\section{2 .3 Wool}

The toxicological results from the flaming wool exposures are illustrated in figure 14 and summarized in table 6. In this case $C O$ is somewhat higher than in the modacrylic, with the CO and HCN concentrations sufficient to be of some toxicological significance but neither alone being sufficient to cause incapacitation.

Figures 15 and 16 are plots of total mass loading vs. toxicological response for flaming and non-flaming combustion. The curves were drawn as a best fit to the data points. However, the values recorded in table 6 were obtained from a statistical analysis of the data according to the method 
of Litchfield and Wilcoxon [7]. In the case of flaming wool (fig. 15) it is interesting to note that the animals in a given experiment were either all incapacitated or none were incapacitated thus producing a very steep-dose response curve. The difference in product loading between zero incapacitation and $100 \%$ incapacitation was 22.1 and $22.6 \mathrm{mg} / 1$.

\subsubsection{Polytetrafluorethylene (PTFE)}

The PTFE produced by far the most toxic combustion products of any of the materials tested. All deaths occurred post-exposure. No analysis of carbon monoxide and other gases was made. The fixed gases were not measured because of the possibility of damaging the gas cells in the non-dispersive IR equipment.

The fatality data for PTFE are summarized in table 6 and in figure 17 in which the time of death and number of deaths is recorded with the sample mass loaded. Incapacitation did not occur during the 30 minutes of the exposure at these concentrations. The highest coHb recorded with this material was $2.4 \%$. The cause of death has not been established at this time, however, the mode of death is suggestive of a CNS (Central Nervous system) type of agent. Review of past work of the toxicity of thermal degradation products of PTFE indicates that the toxicity is attributed to a hydrolyzable fluoride [1]. However, we have not identified the toxic species.

\subsubsection{Flexible Polyurethne (GM-21)}

While the studies on non-flaming GM-2l are incomplete, preliminary analytical and toxicological results show that hydrogen cyanide is not a significant factor. Even at 30 to $40 \mathrm{mg} / \mathrm{l}$ mass loading, the HCN levels never exceeded $30 \mathrm{ppm}$. Carbon monoxide was elevated and $\mathrm{COHb}$ values were in the range of $55 \%$. This was not an incapacitating level or a lethal level for the 30-minute exposure period, however, post exposure deaths did occur.

The fatality data are shown in figure 18. The cause of death was believed due to severe respiratory distress with some of the animals dying as long as 15 days after exposure. In all cases, the animals were weighed daily and as a result of the exposure many lost considerable weight (i.e. as much as 100 grams).

Further analysis of data and more experiments are planned. We also plan to do histology of the respiratory tissues of the exposed animals.

\section{SUMMARY AND CONCLUSIONS}

The results of measurements of the toxicity of the combustion products from the four materials that have been tested according to the prescribed toxicology protocol are summarized in table 7 and figure 19. As indicated earlier, in our experimental system the primary toxicity of the combustion product from the modacrylic fabric can be attributed to HCN. In the case of the wood, it is not so clear. In fact, the average concentrations of $\mathrm{HCN}$ at the $\mathrm{EC}_{50}$ level for the non-flaming wool is almost identical with the LC 50 (30 min.) concentration of $\mathrm{HCN}$ in non-flaming modacrylic. There are at ${ }^{5}$ least two possible reasons for this difference in the toxicological response to the combustion products of wool and modacrylic at the same HCN concentration: (I) an additional unidentified toxic product could be generated in the nonflaming combustion of the wool that somehow protects the animals from HCN. Additional research is required to elucidate these differences.

In figure 19, the $\mathrm{EC}_{50}$ and two $\mathrm{LC}_{50}$ values are compared for the four materials. This comparison shows that 50 nder the test conditions used in these experiments the combustion products from the modacrylic fabric tested 
are about an order of magnitude more toxic than wood and that the PTFE powder used is more than a hundred times more toxic than wood. This correlation appears to be true for all the end-points that were used in these experiments. It is clear, from these data and previous dose-response calculations, that for the materials studied the $E_{5}$ and the $L_{5} C_{50}$ values give above the same information. That is, the incapacitation model is not providing significantly enhanced sensitivity to detect the toxicity of combustion products. This conclusion should not be extended to all materials until data on other materials have been obtained. However, this data does suggest that the proposed test method can be simplified by reducing the amount of incapacitation data that is required.

Overall, the proposed test method gives repeatible results. Mixing in the chamber is rapid and concentration gradients are not significant.

The combined use of analysis of specific toxic products and toxicological data provides a powerful tool for gaining insights into the toxicity of the combustion products of a given material. 


\section{REFERENCES}

[1] Birky, M. M., Hazard characteristics of combustion products in fires: the state-of-the-art review, Nat. Bur. Stand. (U.S.), NBSIR 77-1234 (1977).

[2] Potts, W. J. and Lederer, T. S., J. Comb. Toxicology, 4 , 114-162 (1977).

[3] Q'Mara, M. M., Combustion of PVC, paper presented at the International Symposium of Physiological and Toxicological Aspects of Combustion Products, University of Utah, Salt Lake City, Utah, March 1976.

[4] Paabo, M., Birky, M. M. and Womble, S. E., J. Comb. Toxicology, 6, 99108 (1979).

[5] Valentour, J. C., Aggarwal, V. and Sunshine, I., Anal. Chem., 46, 924925 (1974).

[6] Feldstein, M. and Klendshoj, N. C., J. Lab. Clin. Med., 44, 166-170 (1954).

[7] Litchfield, J. T. Jr., and Wilcoxon, F., J. Pharmacol, and Exp. Therapeut. 96, 99-113 (1949).

[8] Horiuchi, J. and Tanabe, K., J. Research Inst. Catalysis, Hokkaido Univ. 1, 117-131 (1951).

Treported in Seidell, A., Solubilities of Inorganic and Metal Organic

Compounds 4 th Ed., D. Van Nostrand Co. New York, vol. 1, p. 1106 (1958).

[9] Schneider, C. R. and Freund, H., Anal. Chem., 34, 69-74 (1962).

[10] Rodkey, F. L. and Robertson, R. F., J. Comb. Toxicology, 6, 44-47 (1979). 


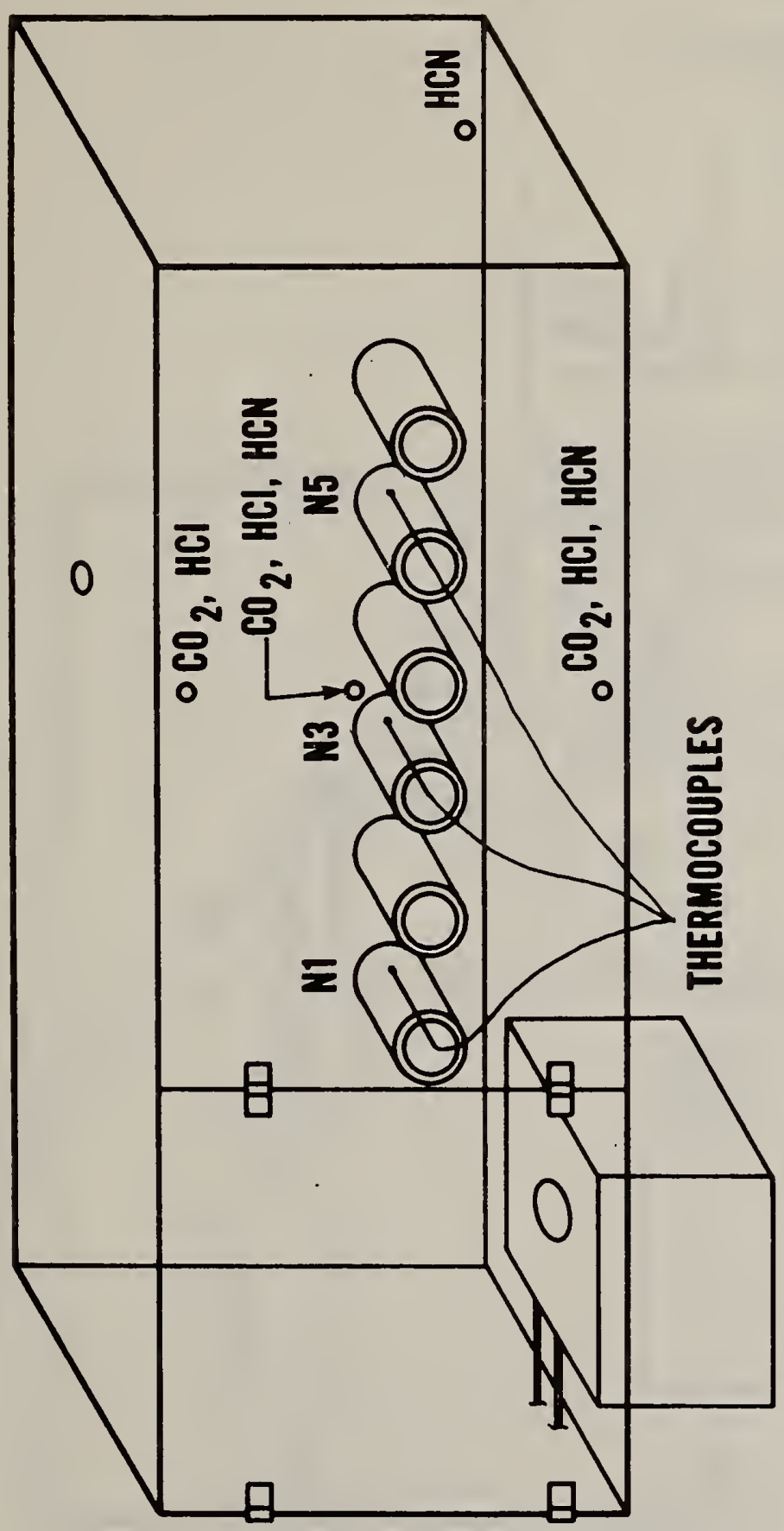

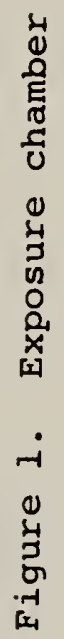




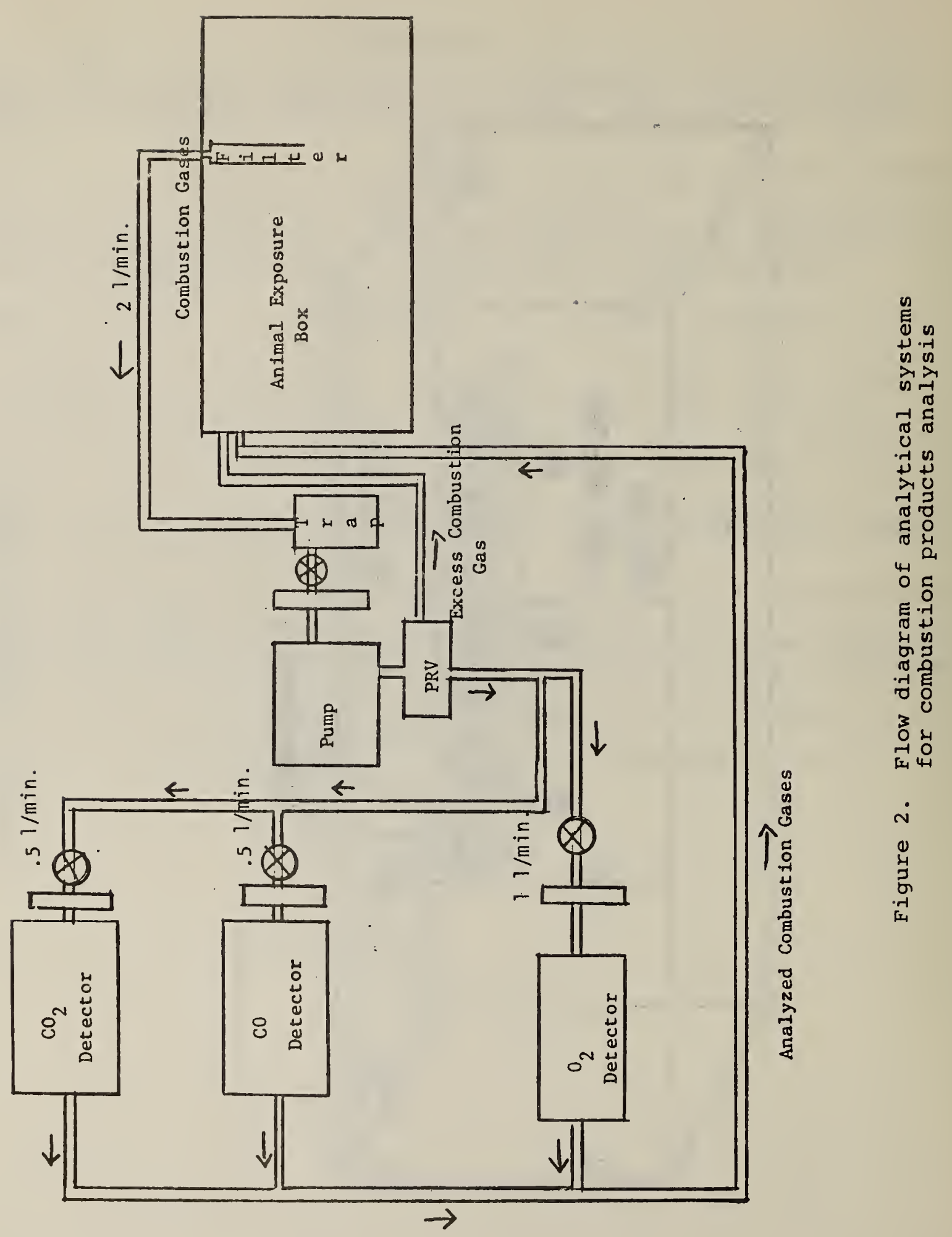




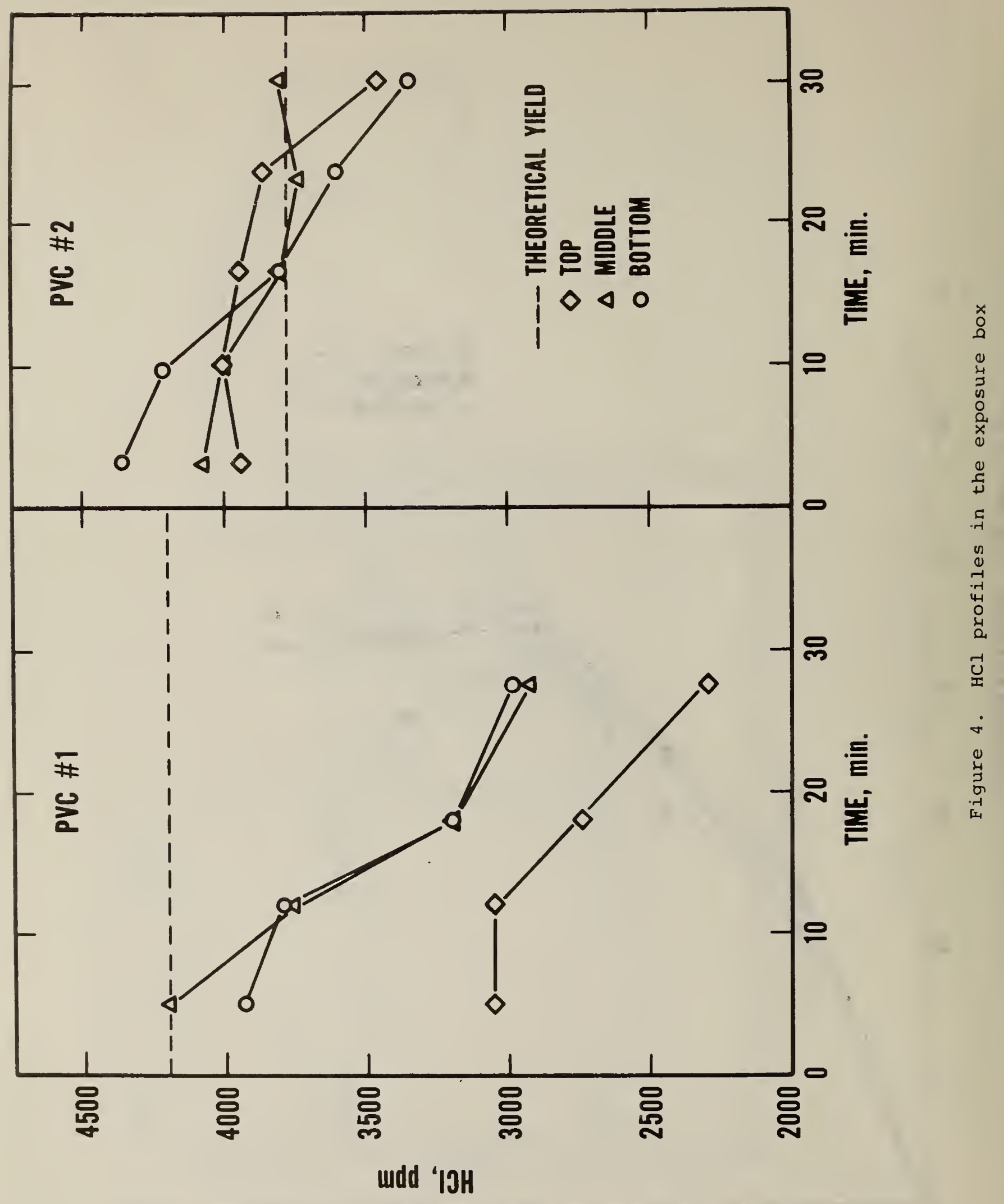




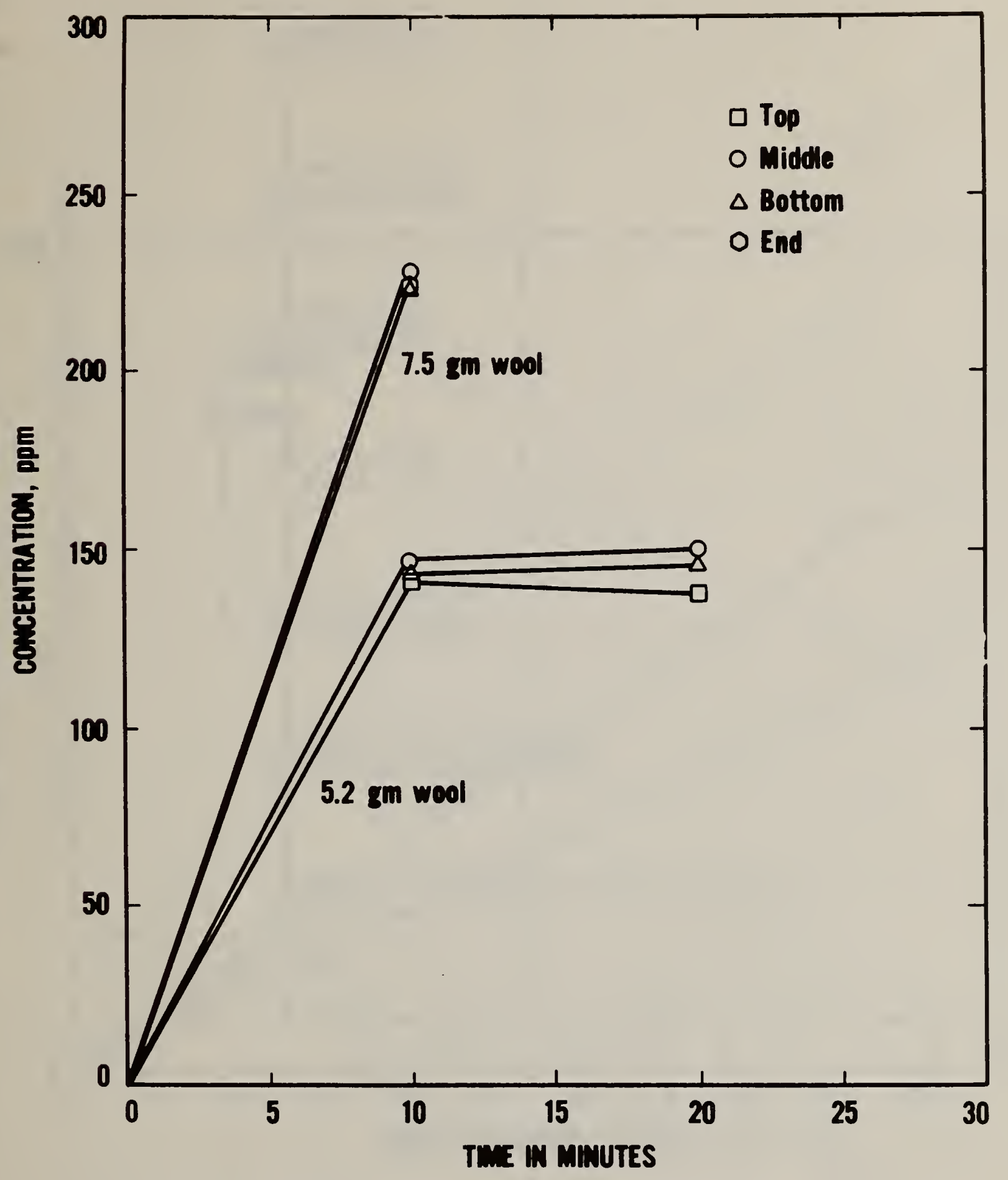

Figure 5. HCN profiles in the exposure box 


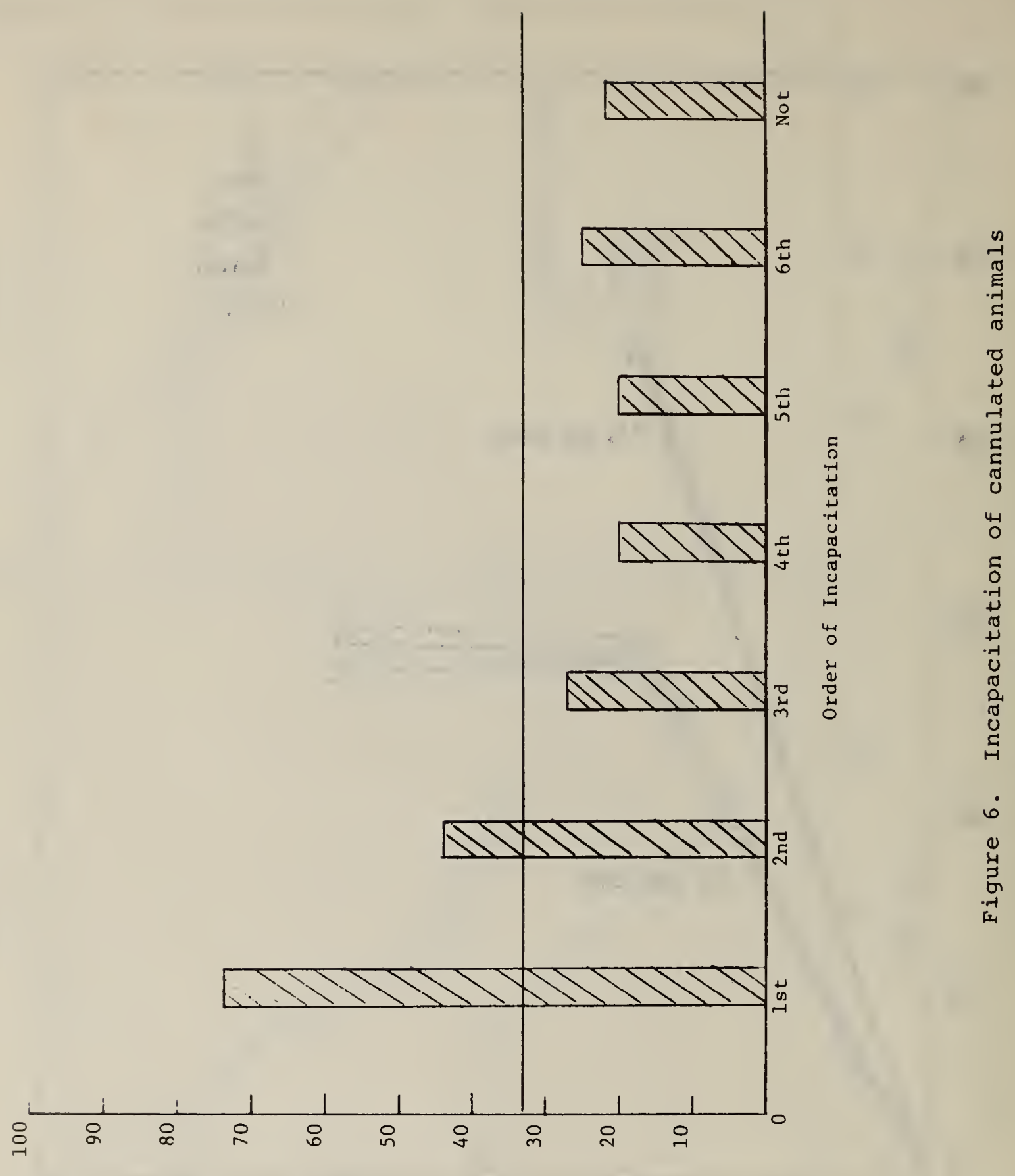

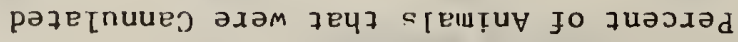




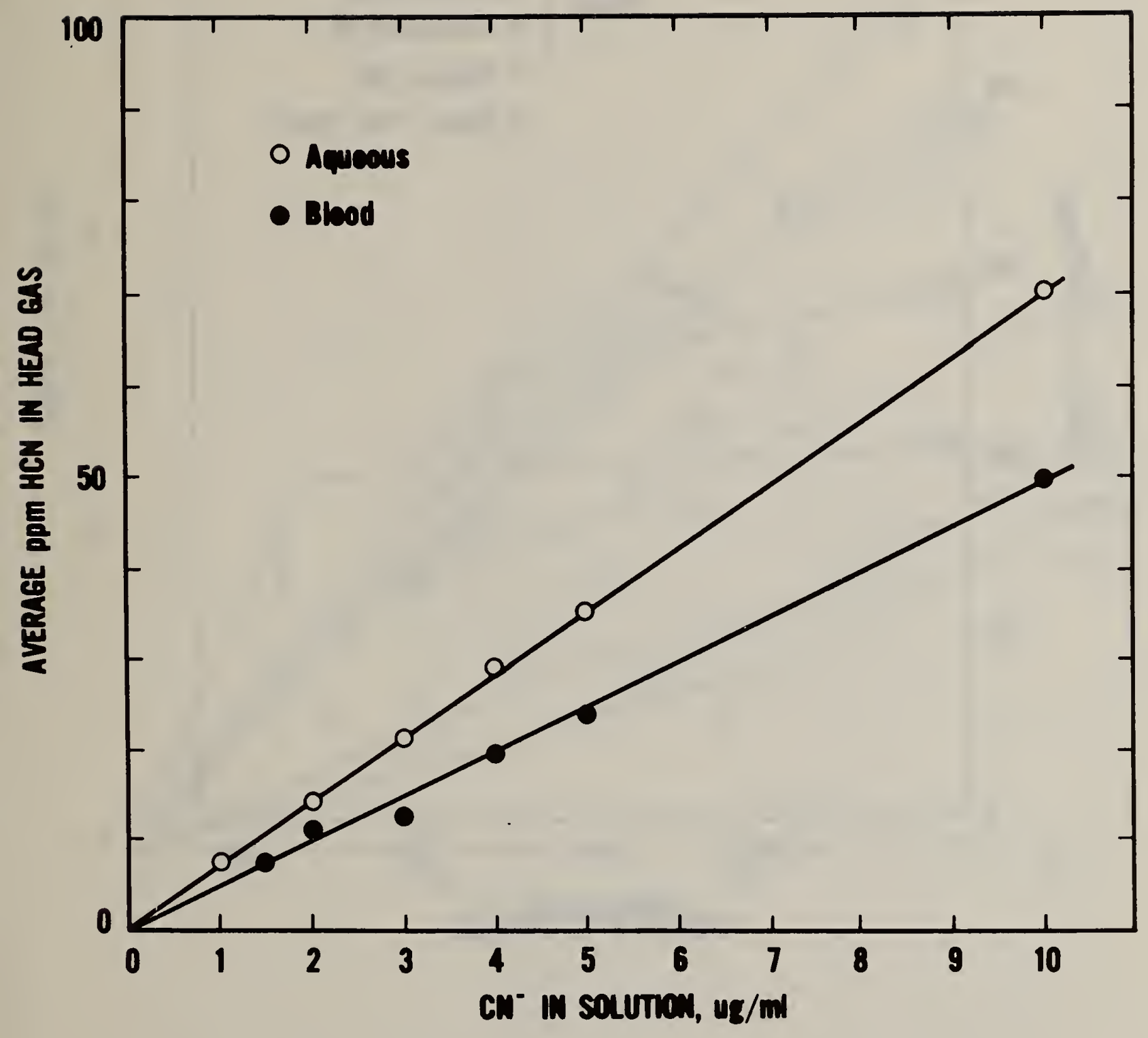

Figurs 1. Head space analysis of $\mathrm{HCN}$ 


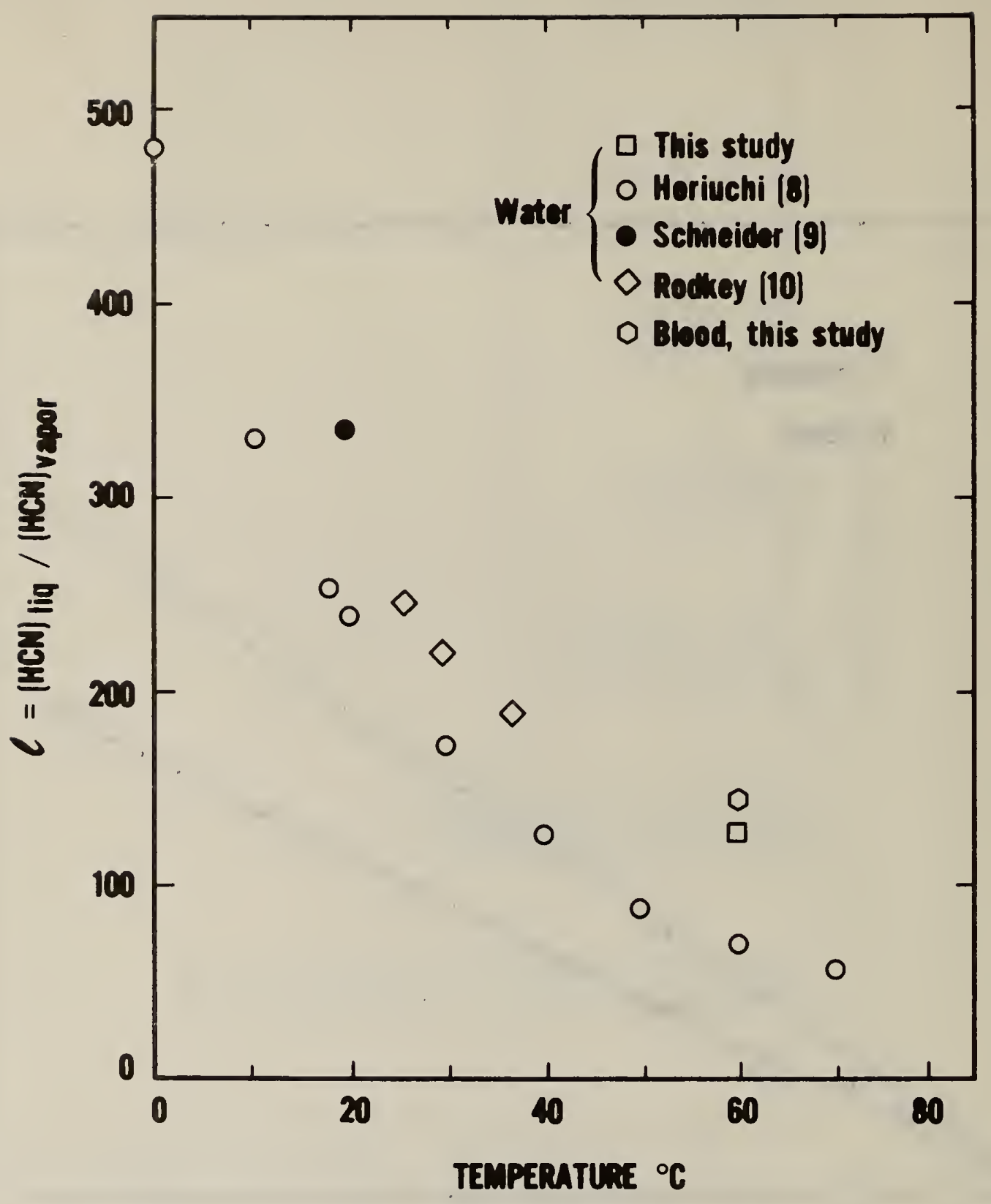

Fiqu D Snluility of $\mathrm{HCN}$ in water 


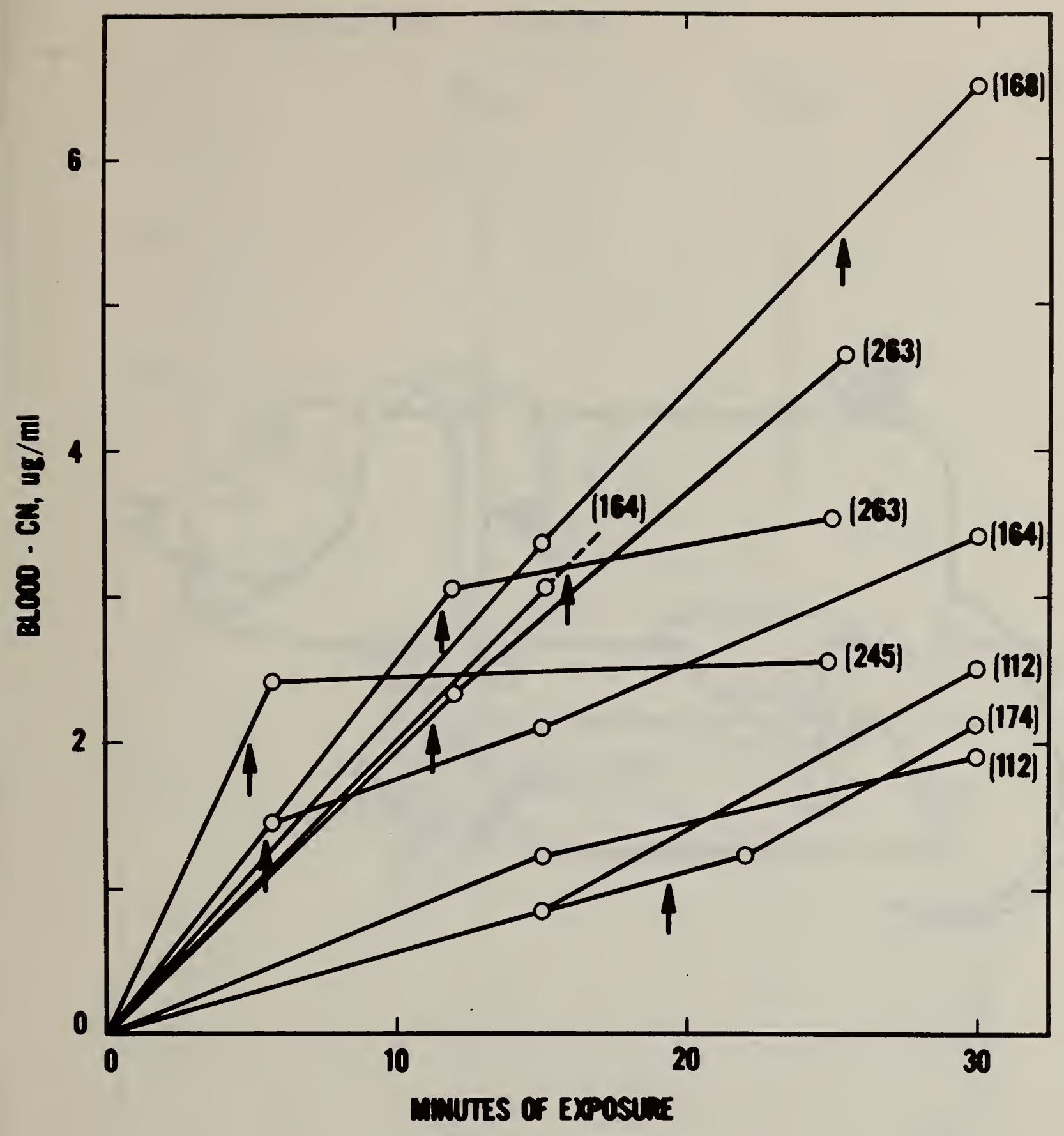

Figure 9. Change in blood cyanide content during exposure to flaming modacrylic (numbers in parenthesis refer to average environmental HCN concentration in ppm. Arrows refer to time of incapacitation. Closed circles refer to rats). 


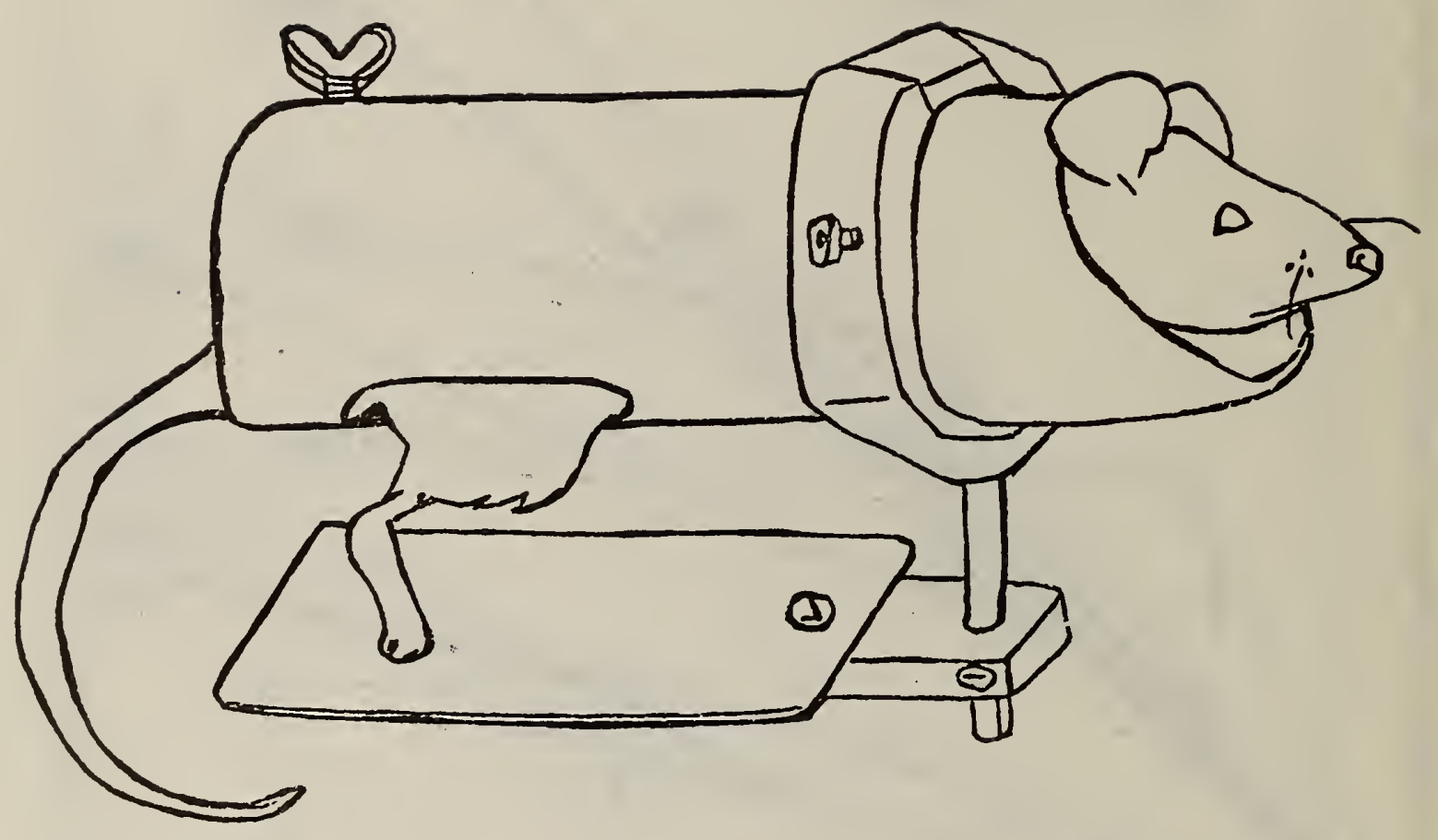

Figure 10. Restrainer for rats 


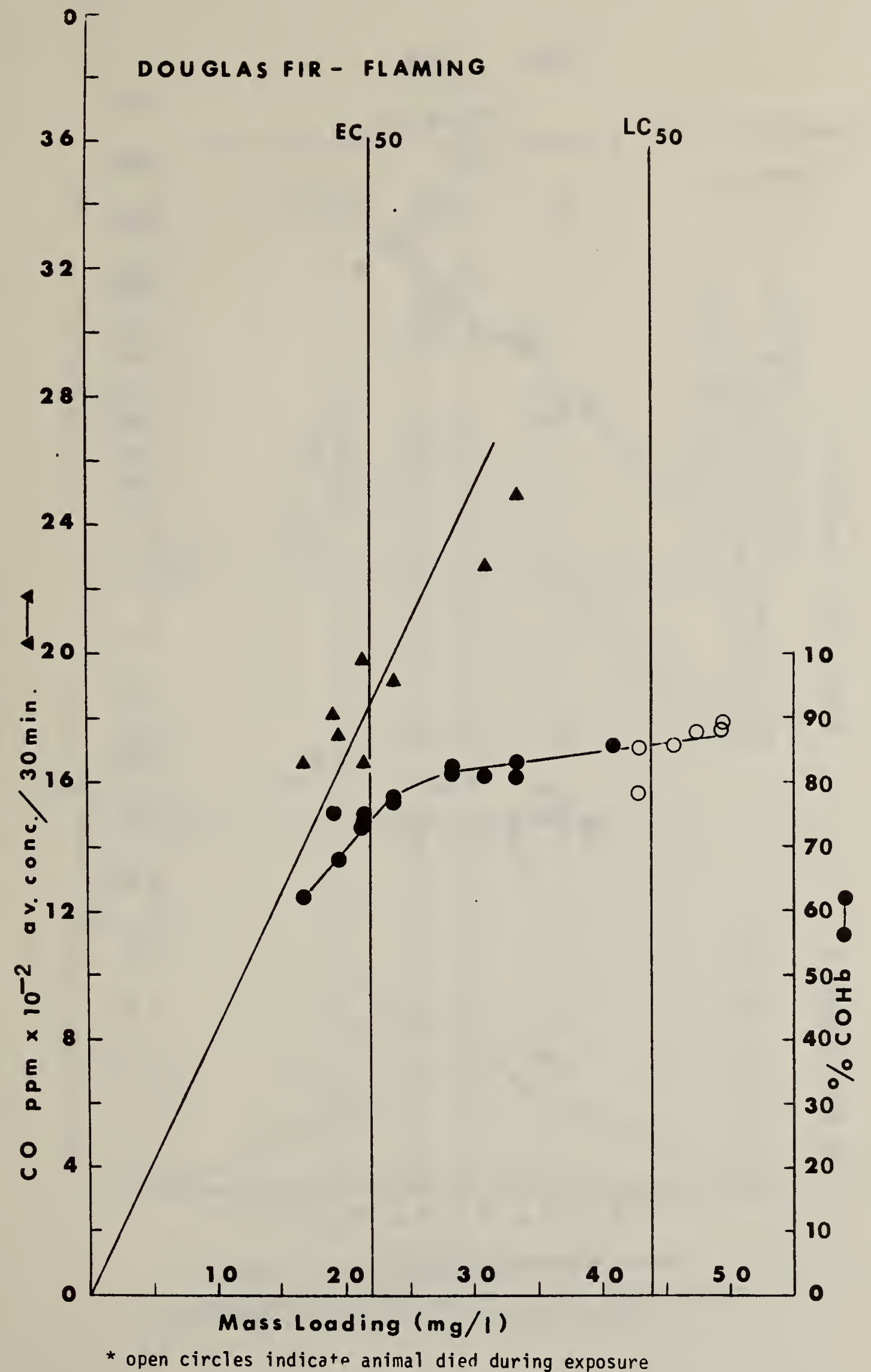

Figure 11. Atmospheric and blood levels of carbon monoxide at different mass loadings of Douglas $f$ ir decomposed by flaming combustion 


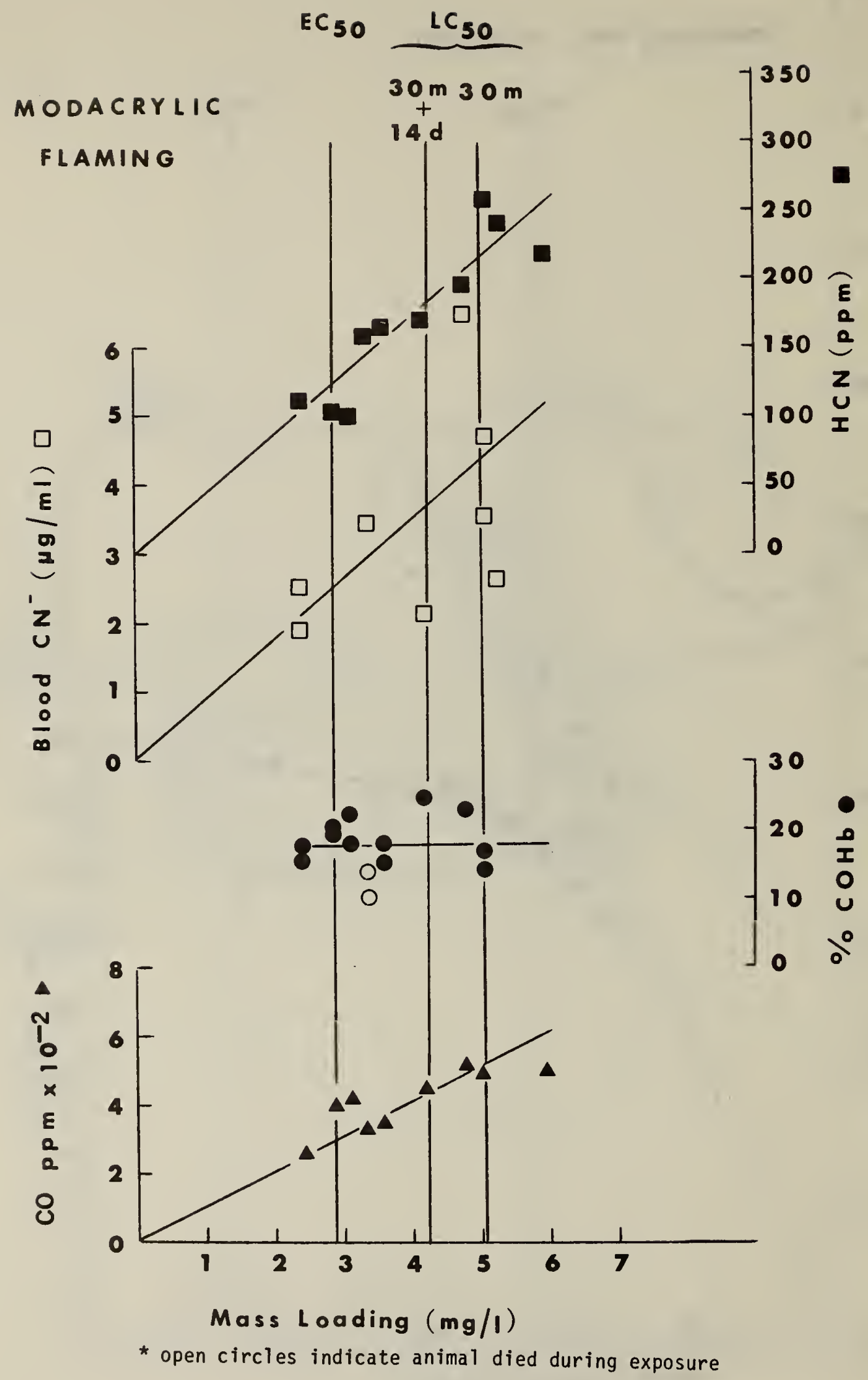

Figure 12. Atmospheric and blood levels of carbon monoxide and cyanide at different mass loadings of modacrylic decomposed by flaming combustion 


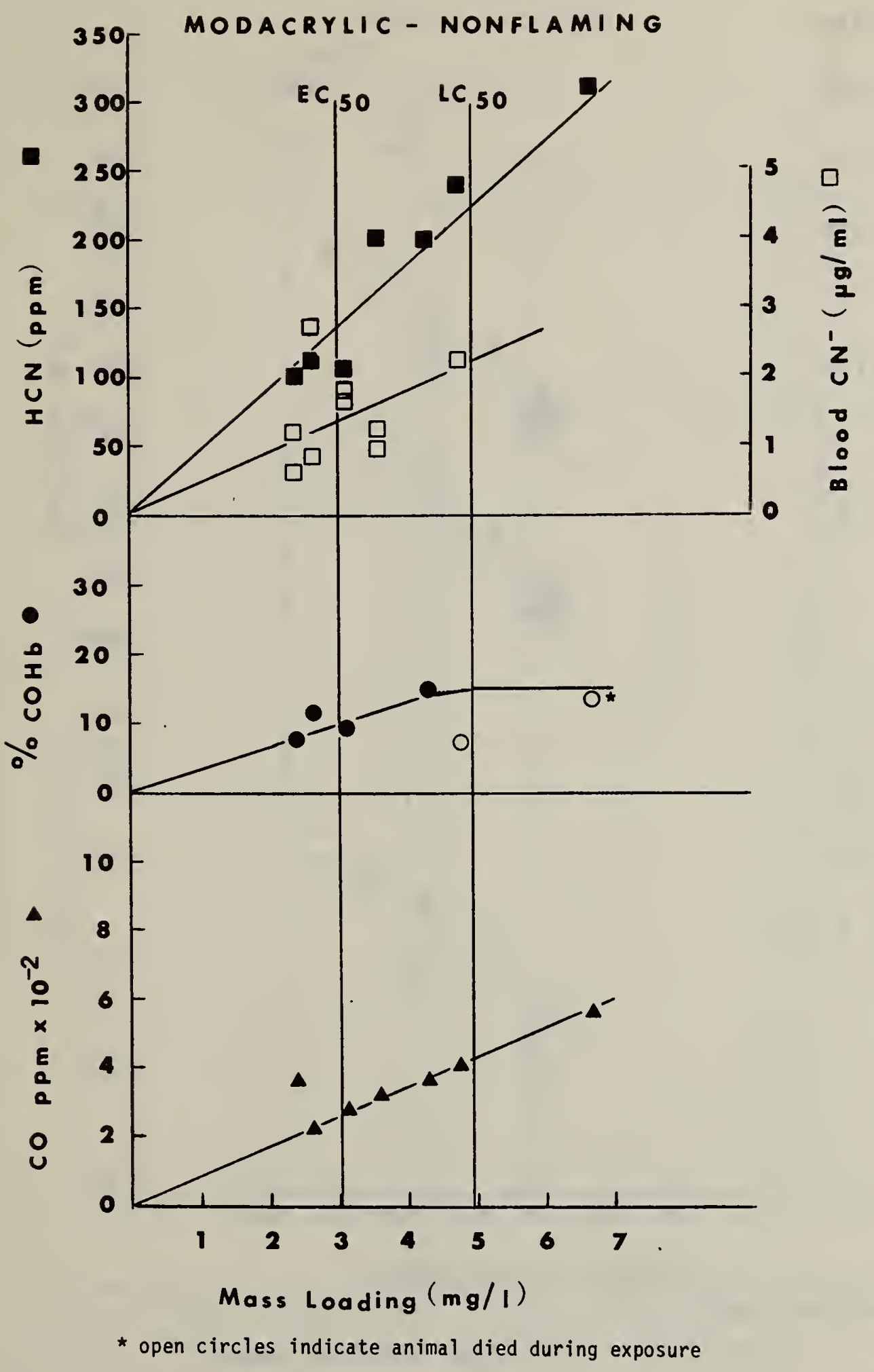

Figure 13. Atmospheric and blood levels of carbon monoxide and cyanide at different mass loadings of modacrylic decomposed in the non-flaming mode 


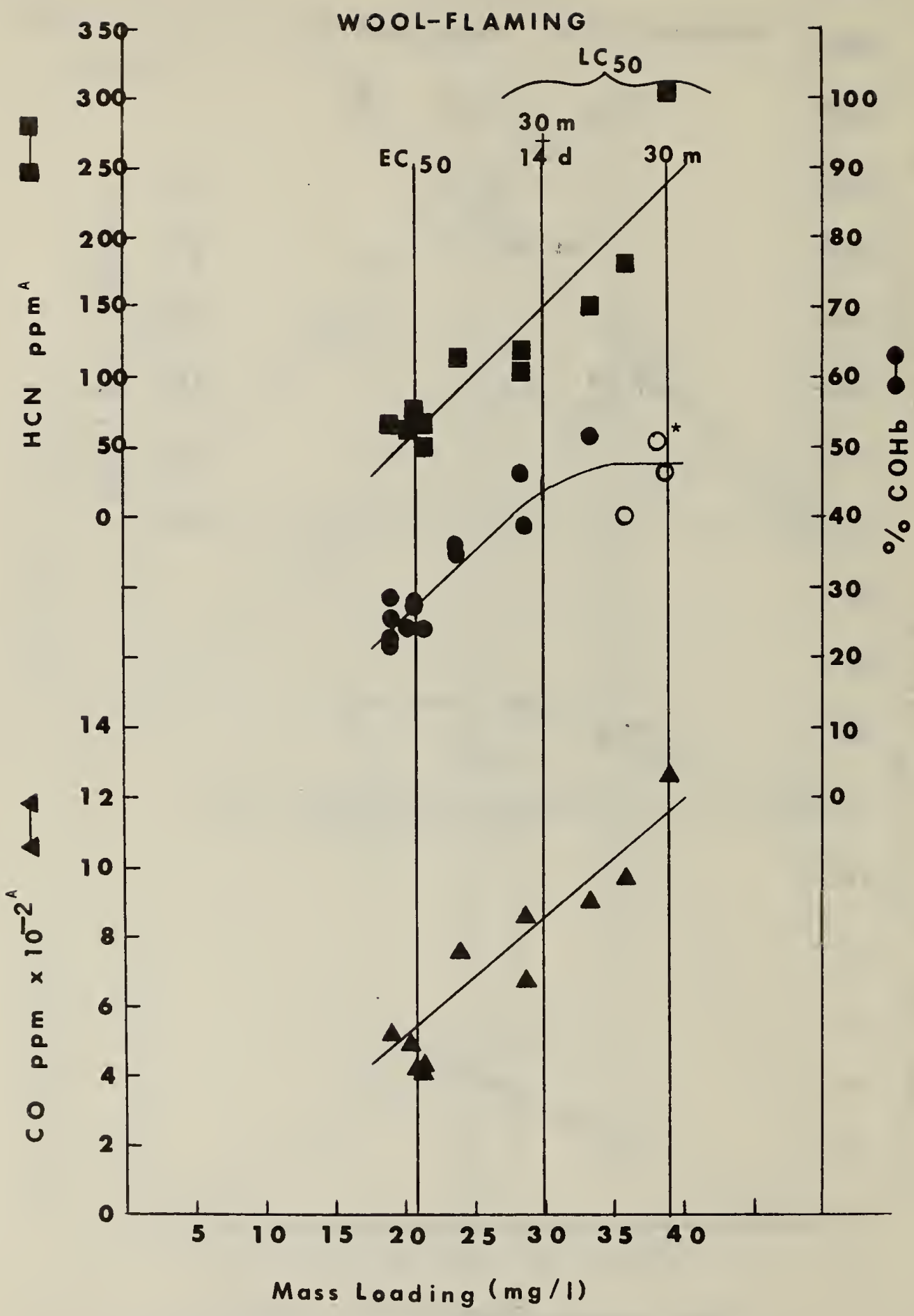

A av. conc. $/ 30 \mathrm{~min}$.

* open circles indicate animal died during exposure and cyanide at different mass loadings of wool decomposed in the flaming mode 
WOOL - FLAMING

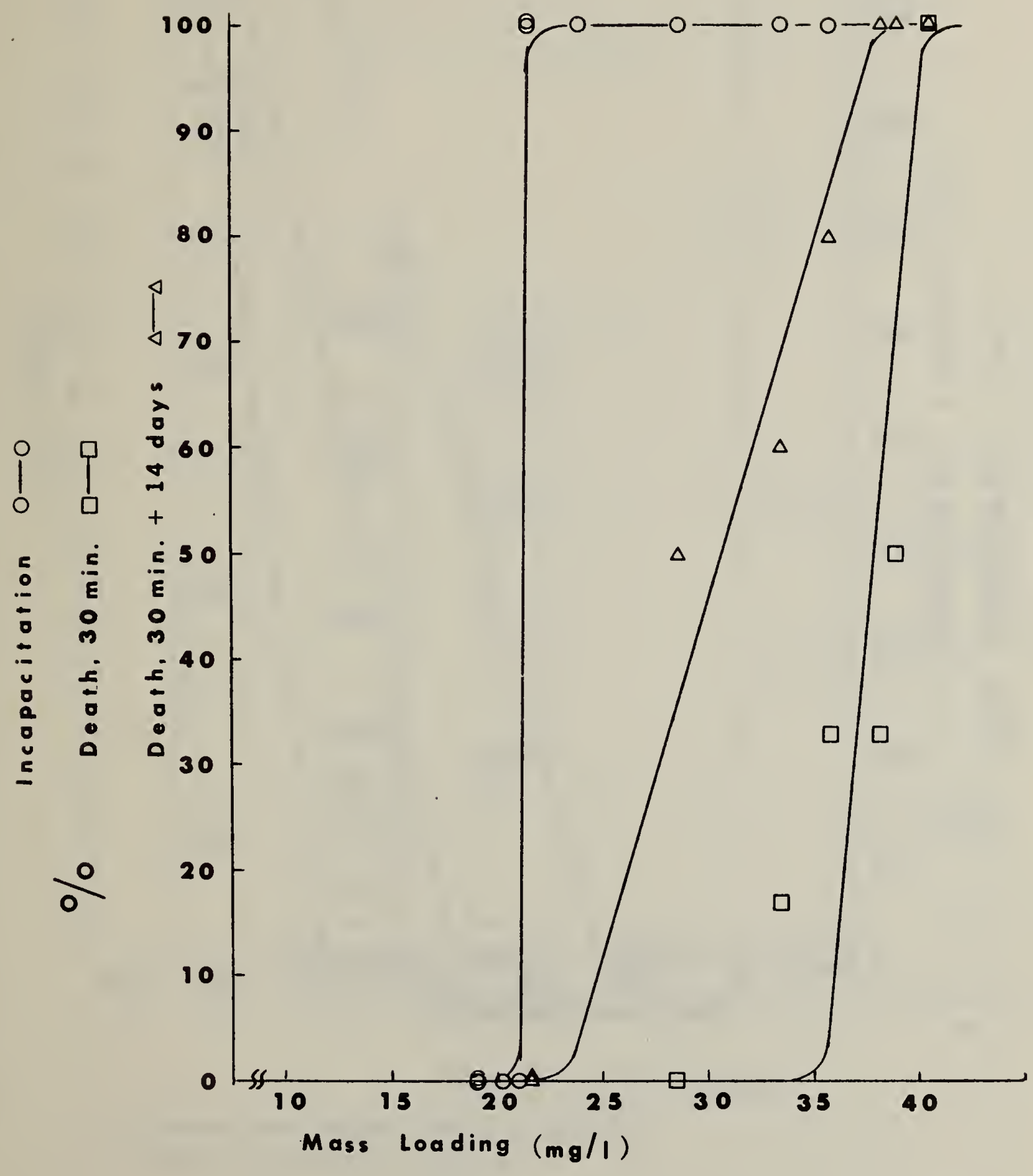

Figure 15. $\%$ incaparitation and 8 death at different mass loadings of wool in the flaming mode 


\section{WOOL - NONFLAMING}

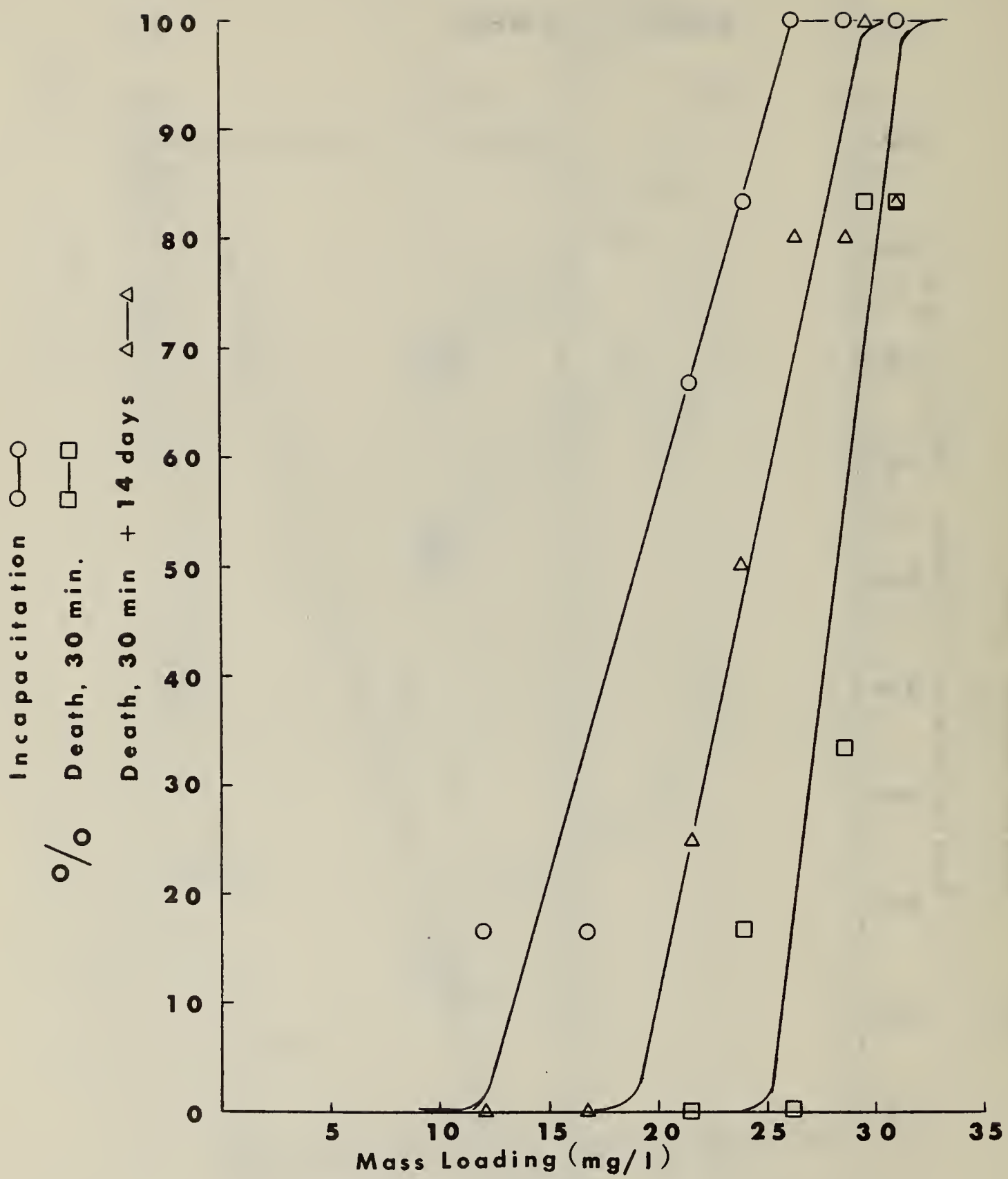

Fidure 16. \& incapacitation and 8 death at different mass loadings of wool in the non-flaming mode 


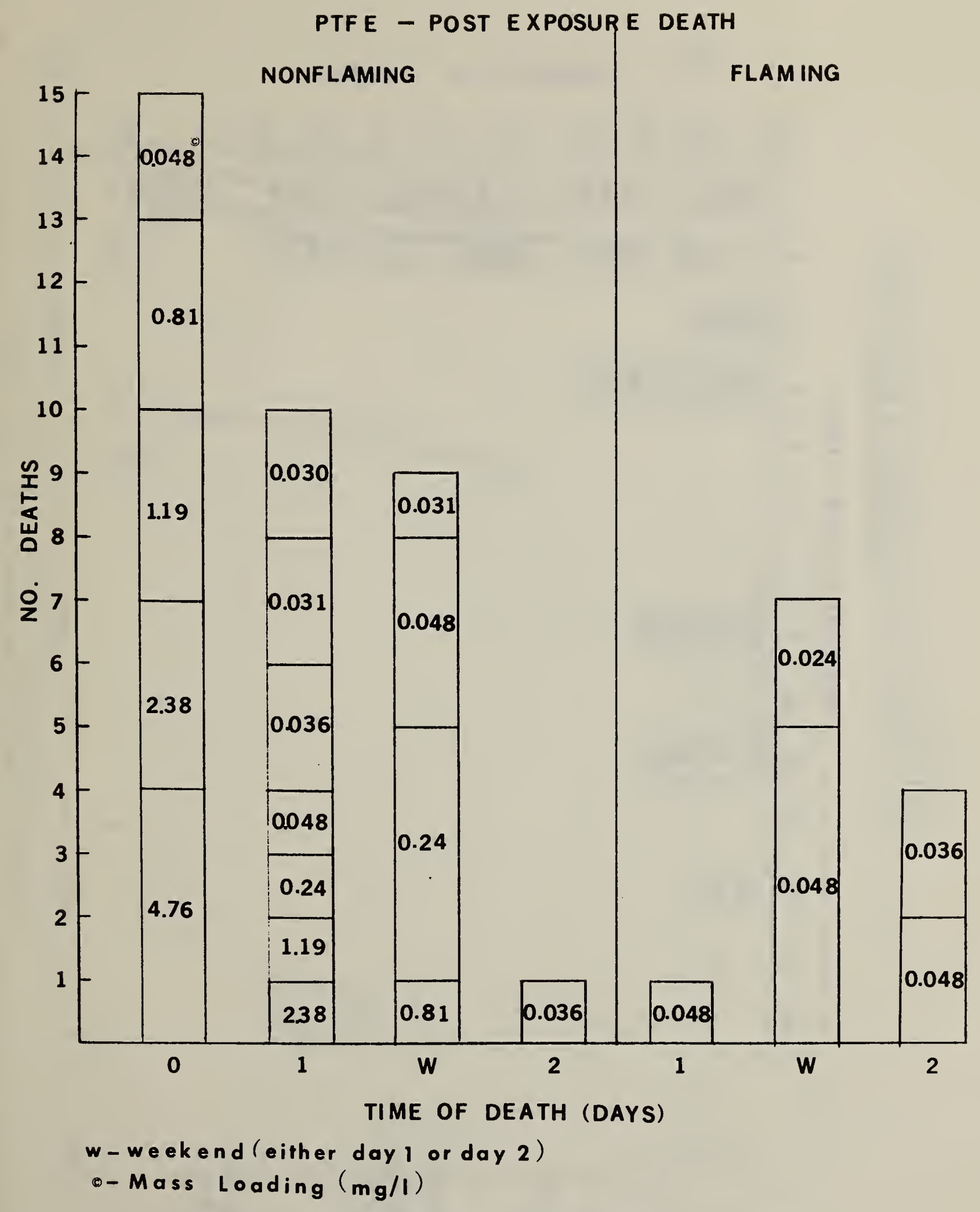

Figure 17. PTFE - post exposure death 


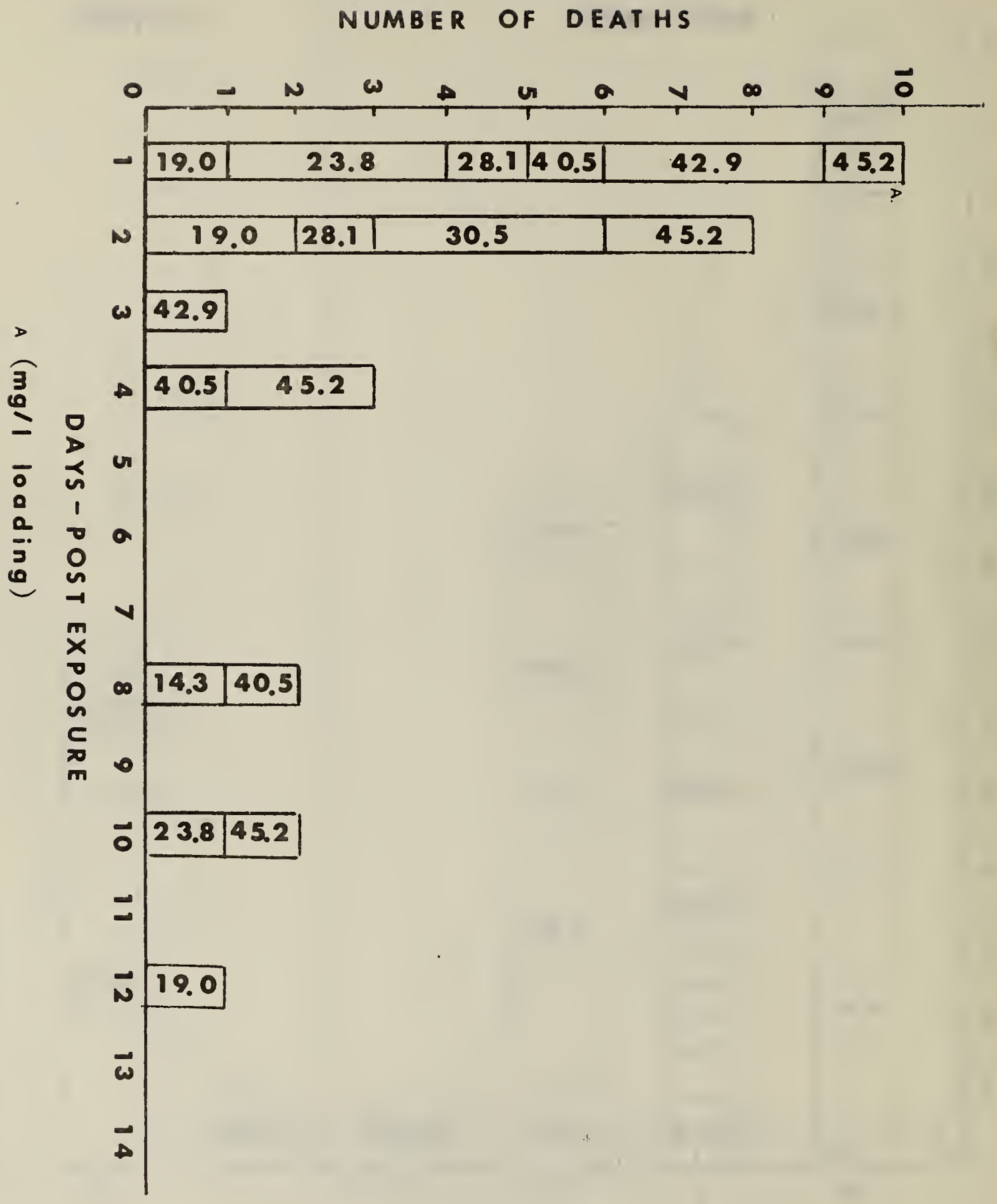

Figure 18. Post exposure mortality from non-flaming flexible polyurethane foam, (GM-2l) 


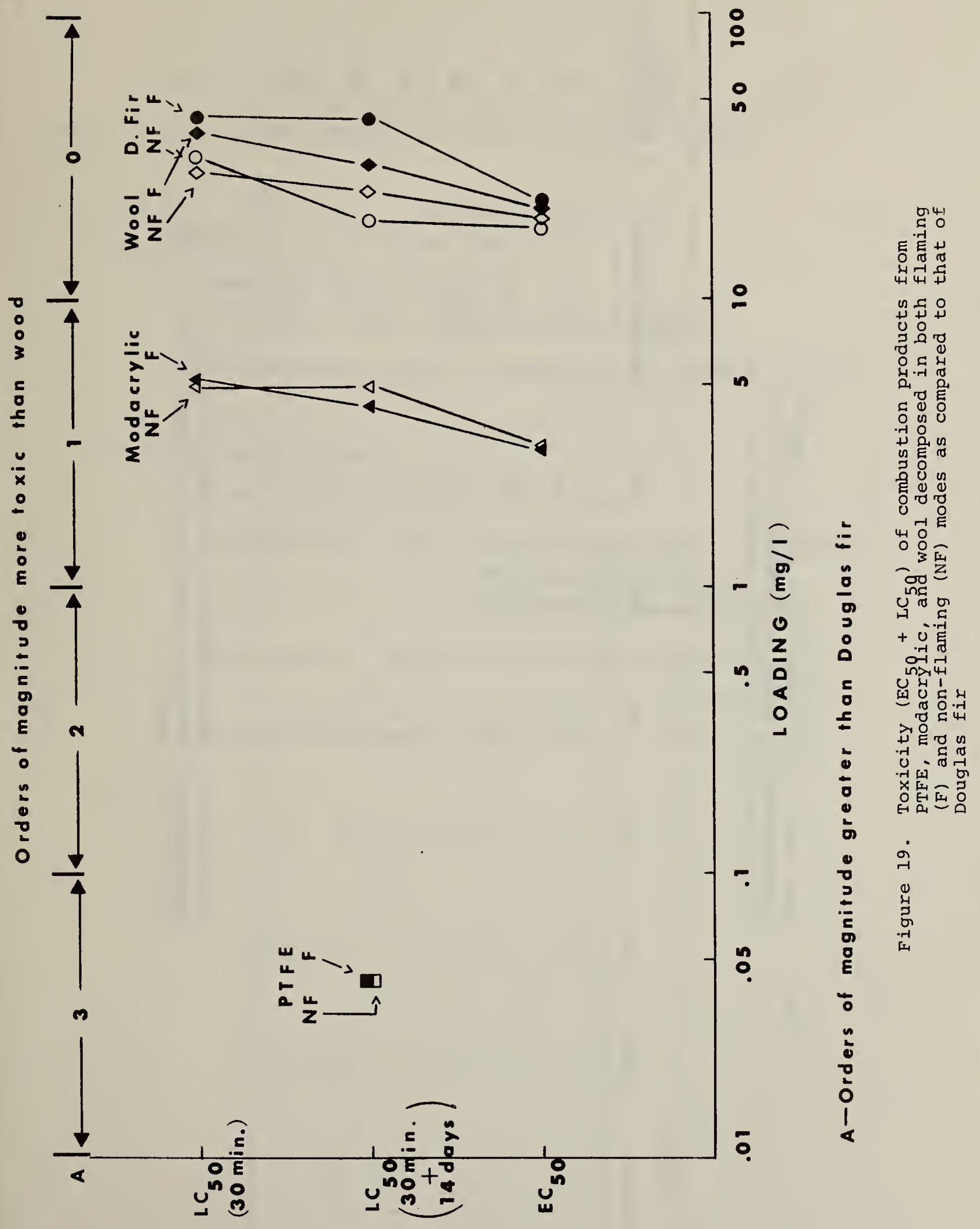




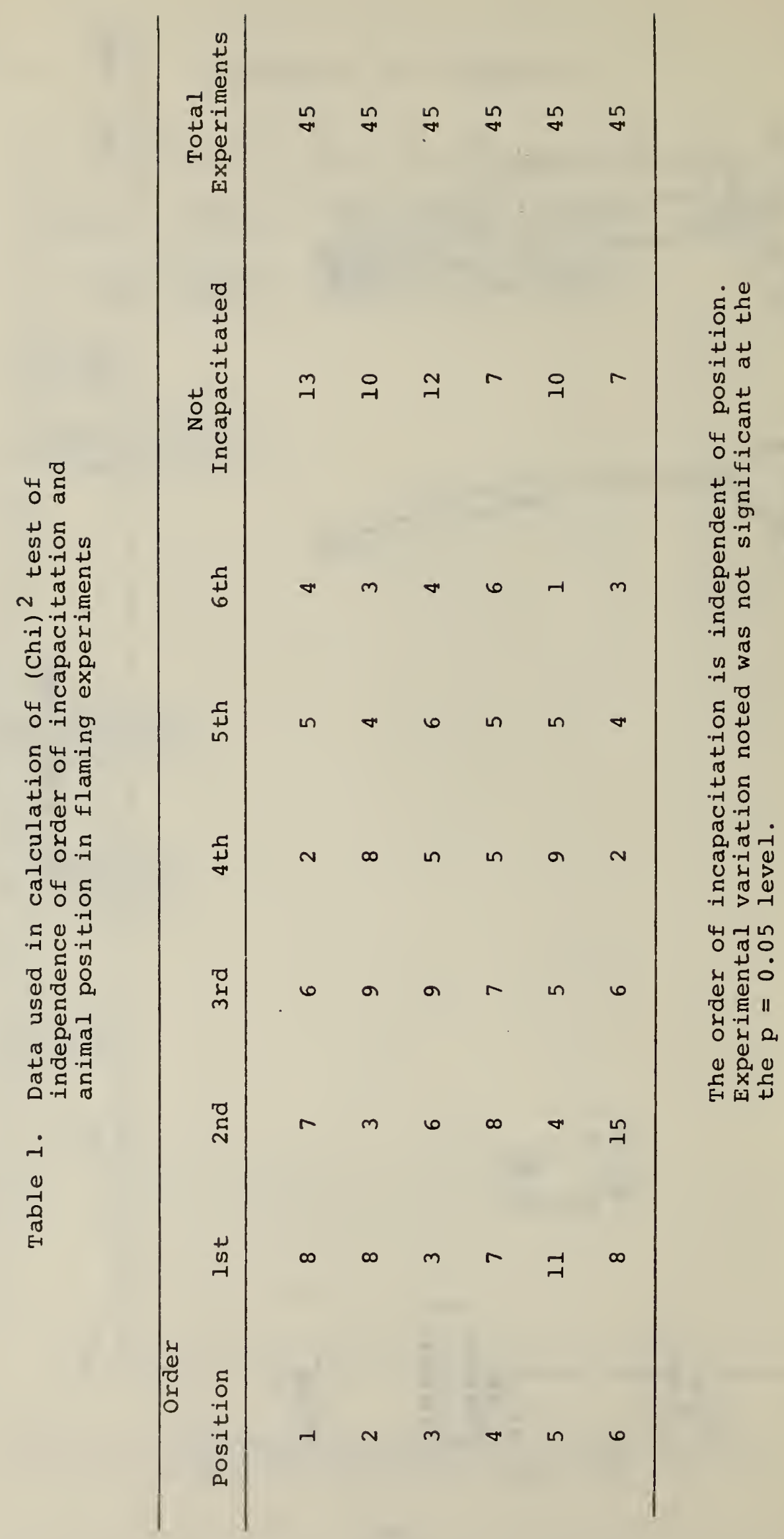


Table 2. Analytical methods for measuring blood cyanide

1. Separation of HCN from blood

- Aeration ( $5 \mathrm{ml}, 30 \mathrm{~min}$.

- Diffusion flask - Cavette ( $5 \mathrm{ml}, 2 \mathrm{hrs}$.

- Microdiffusion cell - Conway (2 ml, 2 hrs.)

2. Measurement of $\mathrm{HCN}$

- Specific ion electrode $(0.01 \mathrm{ug} / \mathrm{ml})$

- Colorimetry - CNCl + pyrazolone/pyridine (0.1 ug/ml) Benzidine/pyridine phenylene-diamine/pyridine

- Fluorometry - Mg-quinoline sulfonic acid chelate $(0.5 \mathrm{ug} / \mathrm{ml})$

- Gas chromatography - ECD - CNCl (0.01 ug/ml) 
Table 3. Auto-ignition temperatures and temperatures used in the flaming and non-flaming modes

\begin{tabular}{lccc} 
Material & Auto-ignition temp. & Non-flaming & Flaming \\
\cline { 2 - 3 } Douglas fir & $465^{\circ} \mathrm{C}$ & $440^{\circ} \mathrm{C}$ & $490^{\circ} \mathrm{C}$ \\
Modacrylic & $725^{\circ} \mathrm{C}$ & $700^{\circ} \mathrm{C}$ & $750^{\circ} \mathrm{C}$ \\
Polystyrene GM-51 & $590^{\circ} \mathrm{C}$ & $565^{\circ} \mathrm{C}$ & $615^{\circ} \mathrm{C}$ \\
Polyurethane GM-21 & $395^{\circ} \mathrm{C}$ & $370^{\circ} \mathrm{C}$ & $420^{\circ} \mathrm{C}$ \\
PTFE & $620^{\circ} \mathrm{C}$ & $595^{\circ} \mathrm{C}$ & $645^{\circ} \mathrm{C}$ \\
Wool & $650^{\circ} \mathrm{C}$ & $625^{\circ} \mathrm{C}$ & $675^{\circ} \mathrm{C}$
\end{tabular}




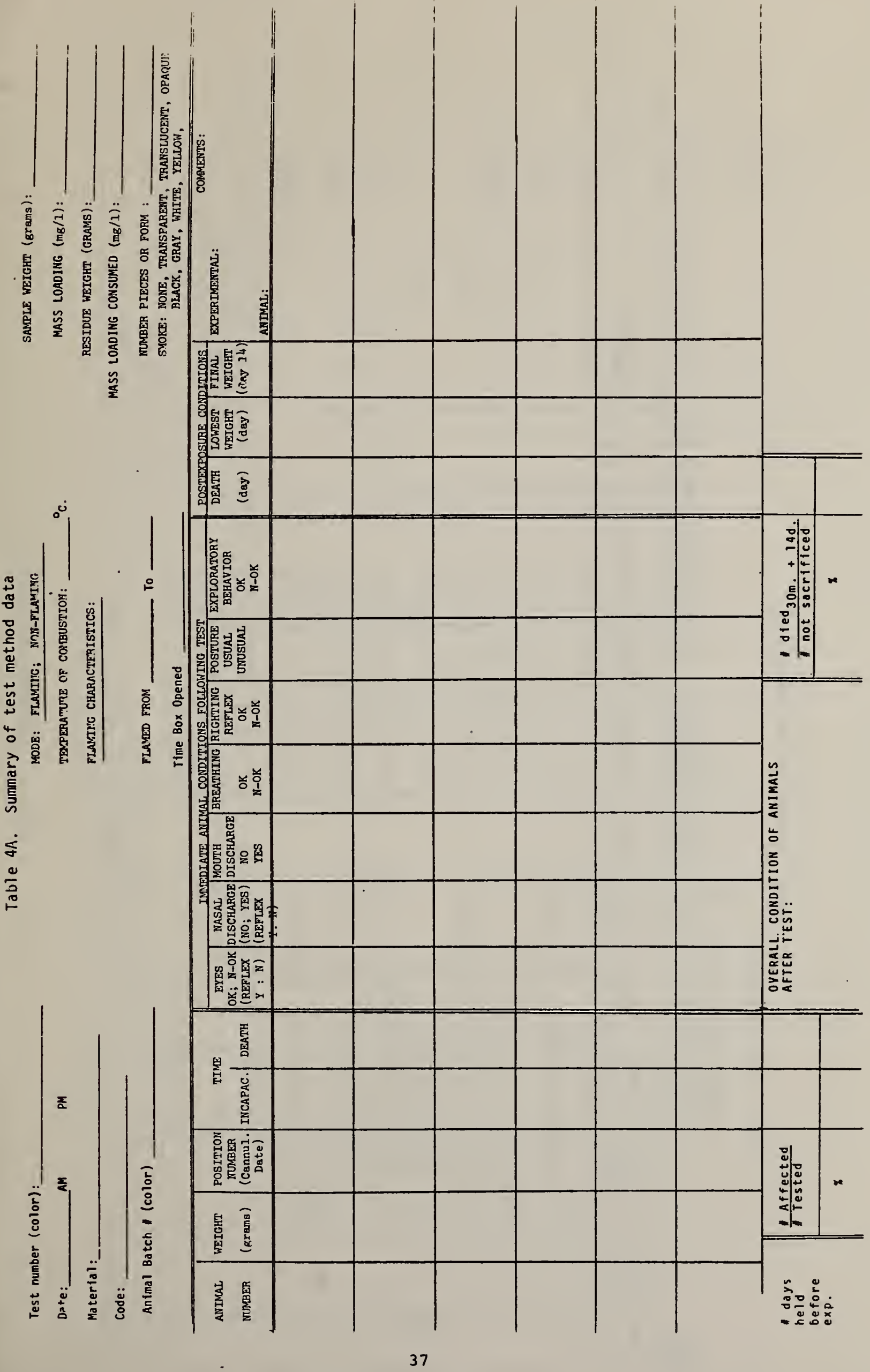




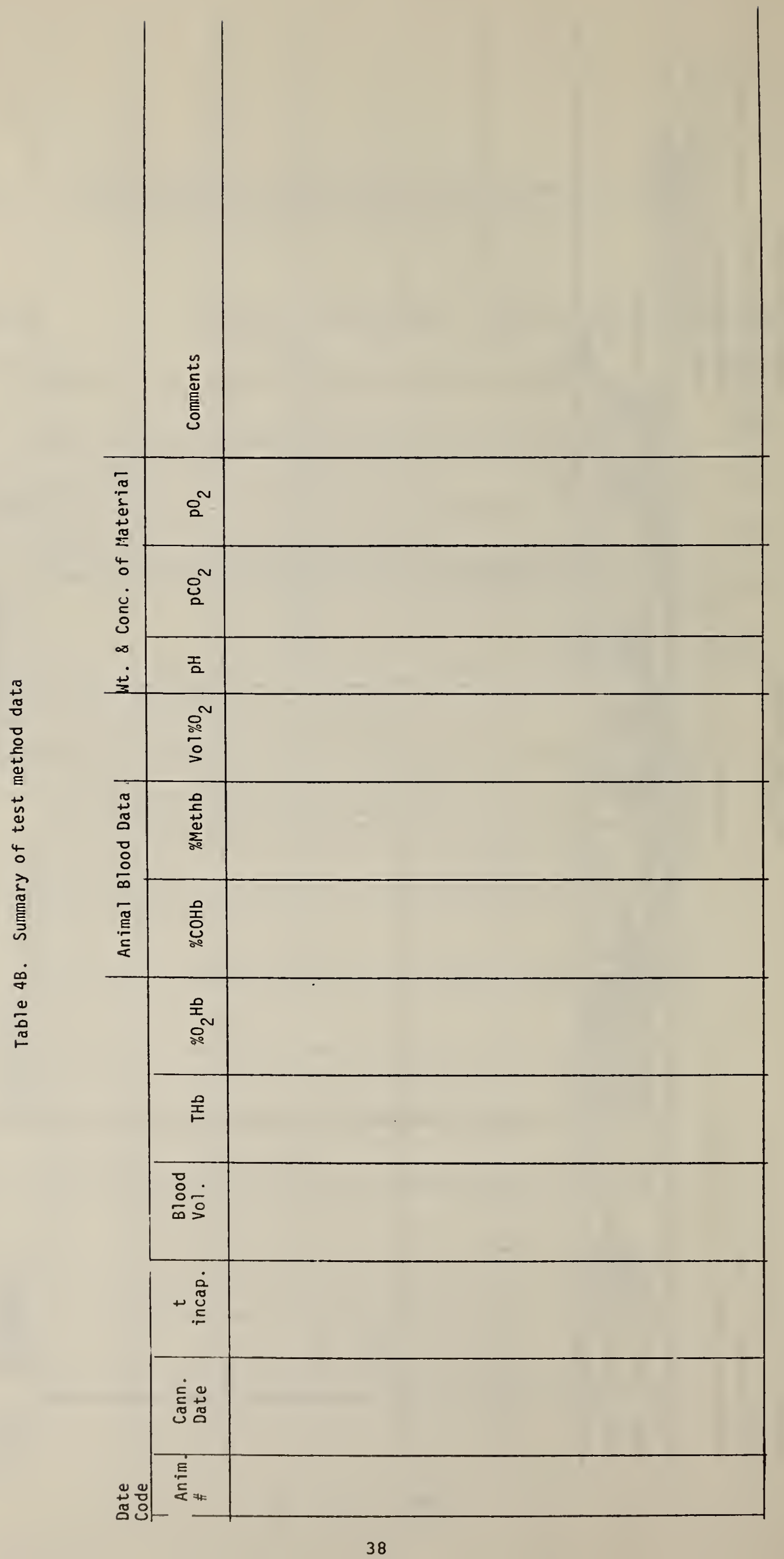




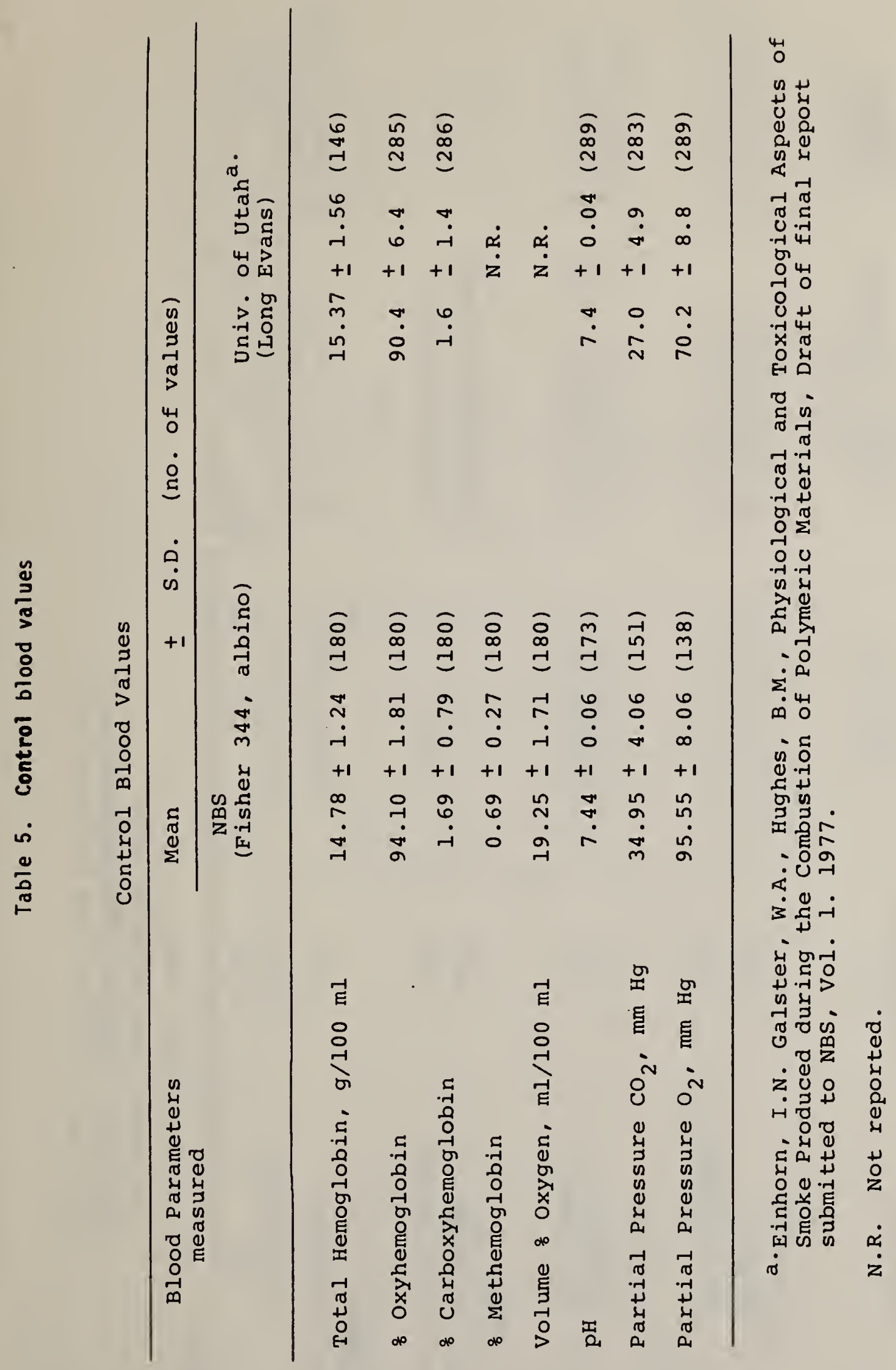



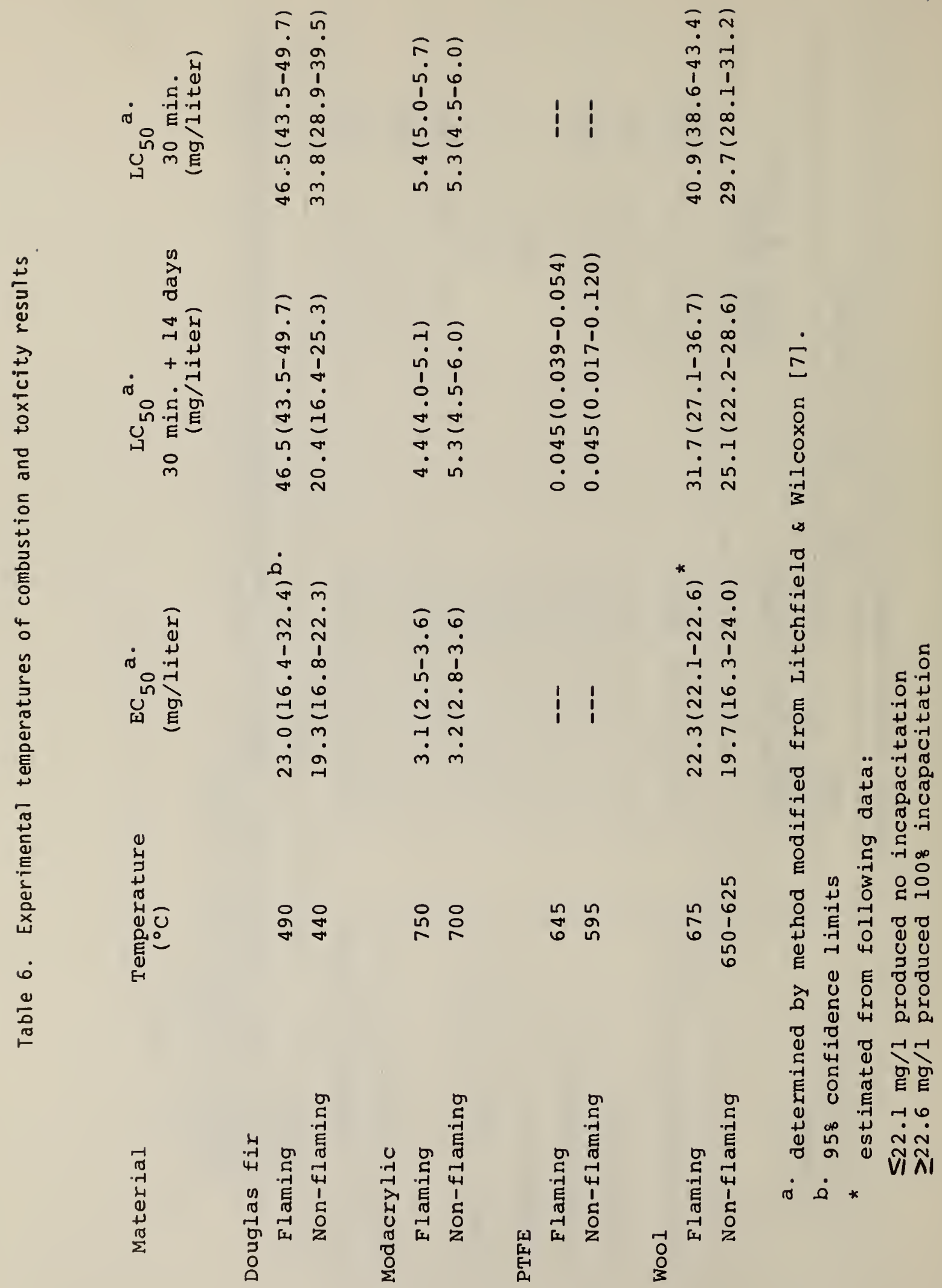


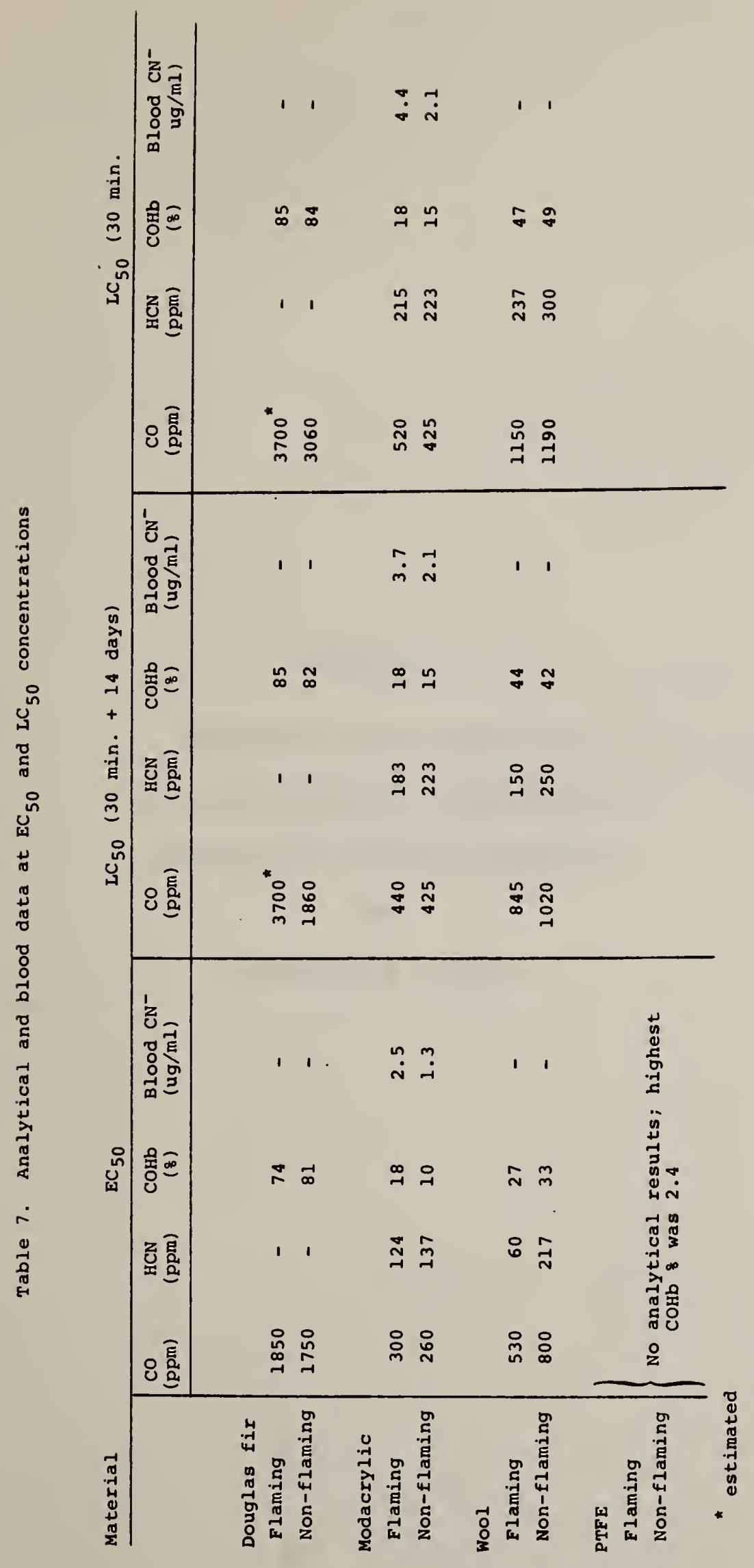





\section{APPENDIX A}

\section{PROPOSED TEST METHOD FOR}

INTERLABORATORY COMPARISON OF

COMBUSTION PRODUCT TOXICITY

by

Merritt M. Birky 
Test Method Outline . . . . . . . . . . . . . . . . iii

1. INTRODUCTION ... . . . . . . . . . . . . . . A-1

2. TEST METHODOLOGY . . . . . . . . . . . . . . . . . A-1

2.1 Animal Model . . . . . . . . . . . . . . A-2

2.1.1 Test Animals ................. A-2

2.1.2 Incapacitation Model ............ . A-2

2.2 Criteria for Test System . . . . . . . . . . . . A-3

2.2.1 Criteria for Animal Exposures . . . . . . . . . . A-3

2.2.2 Criteria for Combustion System . . . . . . . . A-3

2.3 Chamber Design and Construction . . . . . . . . . . . A-3

2.4 Chemical Measurements (Environmental) . . . . . . . . A-4

2.5 Biological Measurements . . . . . . . . . . A A-5

3. DOSE RESPONSE EFFECTS . . . . . . . . . . . . . . . A-5

4. TEST PROCEDURE . . . . . . . . . . . . . . . . A-5

4.1 Sample Preparation . . . . . . . . . . . . . A-5

4.2 Combustion Conditions . . . . . . . . . . . . . A-6

4.2.1 Non-Flaming Conditions . . ... . . . . . . A-6 4.2.2 Flaming Conditions . . . . . . . . . . . A-6

4.3 Exposure Procedure . . . . . . . . . . . . A-6

5. REPORTING OF DATA . . . . . . . . . . . . . . A-8

6. NUMBER OF EXPERIMENTS AND DATA REDUCTION . . . . . . . . . A-8

7. REFERENCES . . . . . . . . . . . . . . . . . A-10

Figure la. . . . . . . . . . . . . . . . . . . . All

Figure lb. . . . . . . . . . . . . . . . . . . . A12

Figure 2. . . . . . . . . . . . . . . . . A-13 
I. Combustion Conditions - Potts Furnace

A. 2 non-flaming conditions

1. $25^{\circ} \mathrm{C}$ below auto ignition temperature

2. $440^{\circ} \mathrm{C}$ if condition $\mathrm{I}$ is greater than $460^{\circ}$

B. I Flaming Condition

1. $25^{\circ} \mathrm{C}$ above auto ignition temperature

(a) add 2 drops of ethanol to sample

(b) use ignition spark or hot coil

II. Sample Conditions

A. Use 1 piece (unless supplied as pellets or granules)

B. Sample conditioning

1. stored for 24 hours at 40 to 508 relative

humidity prior to testing

2. stored at $22-24^{\circ} \mathrm{C}$

III. Animal Model

A. Animal Species

1. adult rats $-200-300 \mathrm{gm}$

(a) male only

(b) 6 required per test

(c) suggested strains: Sprague-Dawley, Wistar

Fisher 344 , (specific pathogen free)

B. End Points

1. time to incapacitation $\left(T_{i}\right)$

(a) based on hind leg flexure paradigm

(b) 2 rats removed at $T_{i}$ if uncannulated

(if cannulated they remain exposed for $30 \mathrm{~min}$. )

2. lethality ( $\mathrm{LC}_{50}$ determination)

(a) 30 minutes plus 14 days post-exposure)

IV. Exposure Conditions

A. 30 minute exposure

B. head only (see chamber)

C. minimum of 3 product concentrations

V. Biological Measurements

A. Ti measure COHb, $0_{2} \mathrm{Hb}$ and total hemoglobin at $\mathrm{T}_{\mathrm{i}}$ on 2 animals

B. \& lethality as a function of product concentration for blood chemistry

VI. Environmental Exposure Chamber Measurements

A. $\mathrm{CO}_{1} \mathrm{CO}_{2}$ and $\mathrm{O}_{2}$ continuously or every 5

1. $21 \% \geq\left(0_{2}\right) \geq 18 \%$

B. temperaEure

1. $22^{\circ} \mathrm{C} \leq \mathrm{T} \leq 35^{\circ} \mathrm{C}$ 



\section{PROPOSED TEST METHOD FOR INTERLABORATORY COMPARISON}

OF COMBUSTION PRODUCT TOXICITY

by

Merritt M. Birky

\section{INTRODUCTION}

The purpose of this test method is to identify those materials that produce unusually toxic or "super" toxic products when the material is thermally degraded. The test method is designed to provide toxicity data in order to classify materials into 2 categories: (1) those producing combustion products of unusual toxicity and (2) those producing combustion products of conventional or moderate toxicity, that is, the toxicity is not significantly greater than wood (Douglas fir).

Since the apparent relative toxicity of combustion products from different materials will depend on the experimental approach and laboratory conditions chosen, small differences in measured toxicity cannot be considered significant in terms of real fire hazard by the present state-of-the-art knowledge in combustion toxicology. Because of these limitations in our present knowledge and experience, this test method, while generally applicable, is designed to identify those materials that produce unusually toxic combustion products as compared to materials such as untreated wood.

The ease with which one can separate the materials into 2 classes will obviously depend on the definition of unusually or super toxic as compared to moderately toxic.

It should be recognized that this proposed test method is still under active study and development. Consequently, it is subject to modification and change.

\section{TEST METHODOLOGY}

The 'selection of a complete system for assessing combustion product toxicity involves many considerations and alternatives. This test method reflects the current state of knowledge which should be recognized as being limited. Any system for assessment of combustion product toxicity must include: (1) a method of product generation, (2) method of exposing animals to these products, (3) chemical analytical measurement system and (4) a measurable response or biological end-point in the experiment.

The design of the combustion and exposure system and the biological endpoint will be strongly influenced by the animal species chosen, the number used in each experiment, and the method of exposure.

The test method includes an animal incapacitation model which should provide the investigator with increased sensitivity and improved discriminatory power with which to assess relative toxicity. However, since no incapacitation model appears to be adequately developed to place full reliance on it, lethality and $\mathrm{COHb}$ level measurements are used at this time. Such questions, as the universality of any given incapacitation model to all combustion products have not been adequately explored. For example, some materials will produce compounds that are primarily sensory and pulmonary irritants, while combustion products from other materials may have a primary effect on the central nervous system, or cardiac system, etc. Thus combustion products from various materials will attack different target organs, and any animal model should measure the overall ability of the animal to escape or survive with signficantly increased sensitivity over a lethality measurement. 
Since the primary route of entry of toxic combustion products into the body is by way of the respiratory tract, the designated approach draws on existing knowledge in respiratory or inhalation toxicology. MacFarland (1) reviewed methodologies in inhalation toxicology, and the approach set forth below draws heavily on his review.

\subsection{Animal Model}

\subsubsection{Test Animals}

Rats were chosen as the animal of choice since a great deal of toxicological data is available. Although similar data are generally available on mice, the selected blood chemical measurements required in the test necessitate the use of the larger animal with the greater blood supply. The use of rats does not mean or imply that a correlation has been established between the effects of fire products on humans and rats.

Male adult rats weighing 200-300 gm are required for the test protocol. Choices of animal strain are Spraque-Dawley, Wistar or Fisher 344 . Specific pathogen free rats should be ordered. The animals are to be kept for observation 10-14 days prior to use. Clinical examination and pathological evaluation of the test animals are mandatory to verify that they are pathogen free. Approximately 1 rat in 10 should be used as a control, sacrificed and inspected for pulmonary pathology. Facilities for housing, care and use of animals must conform to Federal guidelines (2).

The test procedure requires 6 animals per exposure; 2 animals are to be used to obtain blood samples at time of incapacitation or, if not incapacitated, at the end of the 30 minute exposure. The other 4 are for lethality determinations.

\subsubsection{Incapacitation Model}

In the last few years, 3 animal (rat) incapacitation models have been developed to study the toxicity of combustion products. The conditioned avoidance response developed by Packham (3) has been used extensively for combustion product toxicity and carbon monoxide toxicity studies. A second system, the rotating activity wheel has been used by Crane et al. (4) to evaluate combustion products of aircraft cabin materials. A third system, the rotorod, has been used by Hartung et al. (5) to measure the toxicity of a variety of materials.

A review of the limited data available from these 3 methods and discussions with these individuals indicate that they give similar results in terms of toxicity of materials. As each method has both advantages and disadvantages, the choice of one over the other appears to be a matter of personal preference. However, the rotorod and the hind leg flexure are more amenable to quantification through the triggering of an electrical signal at the point when the animal can no longer perform the assigned task. The rotating activity wheel requires visual observation of the animal to determine when the animal can no longer perform the assigned task and with some materials smoke may obscure this observation.

In a preliminary in-house comparison of the activity wheel and the hind leg flexure methods, animals exposed to wood, polyurethane or polyvinylchloride combustion products showed nearly equivalent incapacitation times.

Similar comparison of the rotorod incapacitation model has not been done inhouse.

The hind leg flexure paradigm was selected for this test method because of certain advantages or conveniences. At the same time one must realize that there are also certain limitations to this technique that may not arise in 
the other two systems. Future measurements and experience with the various techniques may suggest that one of these three methods, or a totally different system, may clearly offer a superior test method. However, it may be a number of years before enough data and experience are available to make such a decision.

\subsection{Criteria for Test System}

\subsubsection{Criteria for Animal Exposures}

Fxposure period for the test is to be 30 minutes. Heat stress and oxygen depletion are not to be factors in the test method. In order to eliminate heat stress, the chamber temperature should not exceed $35^{\circ} \mathrm{C}$. The chamber temperature at the beginning of an exposure shall be $22 \pm 2^{\circ} \mathrm{C}$ and should not rise above $35^{\circ} \mathrm{C}$ for any time period during the 30 minute exposure. The environmental oxygen level should not fall below $18 \%$.

Heat stress and oxygen depletion are eliminated in order to assess only the "chemical" toxicity of products produced during thermal degradation. These 2 factors, if included, would affect the chemical toxicity significantly, and an exploration of the infinite variations possible would delay a test method for years. For this reason these two parameters are to be controlled within the narrow limits specified.

\subsubsection{Criteria for Combustion System}

Certain minimal requirements are also placed on the method of product generation. It is clear that the 2 distinct modes of combustion (flaming and non-flaming) should be realizable and each mode controlled and explored separately for toxicity. In addition, the heat source (furnace system) must be temperature or heat flux controlled over a broad range. Due to the fact that the exposure is relatively short, the shape of the concentration-time curve becomes important. That is, the concentration of combustion products should peak rapidly and ideally remain constant for most of the exposure period. This means that the combustion products should be generated rapidly and the atmosphere within the chamber equilibrate rapidly. This will obviously depend on the thermal response of the material.

\subsection{Chamber Design and Construction}

Various factors, which influence the chamber design, have to be considered before the chamber can be constructed. These factors are whether the animals are placed in:

(1) a static or dynamic atmospheric exposure and

(2) a head only or whole body exposure mode.

These factors will influence the restrictions on environmental temperature rise in the chamber.

In the static mode, the products are generated in the animal chamber, whereas in the dynamic mode, the products can be generated exterior to the animal chamber and transferred by a blower or compressed air. Each has advantages and disadvantages. In this particular protocol, the static mode was chosen since certain toxic products may be lost by adsorption during transfer in a dynamic system. This mode also requires less material for toxicological evaluations.

Head only exposure was considered advantageous for it minimizes the possibility of heat stress and it allows the investigator to monitor various physiological functions. Head only also minimizes the deposition of toxicants on the animal's fur and the subsequent ingestion of these toxicants by the animals while grooming. On the other hand, whole body exposure, in which

$$
\text { A-3 }
$$


the animals are required to exercise moderately during the test, is advantageous for observation of behavioral changes during the exposure. Whole body exposure also eliminates the stress on the animal caused by the restraint required in the head only technique. After due consideration of all these factors, the head only exposure technique was selected.

The chamber design is shown in Figures $l a$ and $1 b$ and is to be constructed of polymethvlmethacrylate sheet. The inside dimensions are 48 inches long 18 inches high by 14 inches deep. The nominal volume of the chamber is 200 liters. The chamber should be gas tight and checked for major leaks and any leaks corrected. A pressure relief balloon is to be attached to allow for expansion of the gases during combustion of the sample. In addition, a blow-out panel should be incorporated in the chamber. This panel should be a ilexible film, such as mylar or teflon coated aluminum foil.

In the chamber shown in Figure $1 \mathrm{a}$ and $1 \mathrm{~b}, 6$ animals are exposed head only in individual restrainers. Behavioral incapacitation measurements are performed on all 6 animals. Two of the 6 animals must be sacrificed for blood chemistry (COHb) at the time of incapacitation. Alternatively, if two animals are cannulated prior to exposure, then the blood COHb determinations can be determined at the time of incapacitation without sacrificing the animals. In this case, all 6 animals may be exposed for the full 30 minutes.

The combustion module shown in Figure 2 is fitted into the animal chamber as shown in Figure 1. The degradation system is similar to that reported by Potts and Lederer (6) and consists of a small furnace closed at the bottom end. The furnace temperature is controlled with an automatic temperature controller. The temperature is monitored with a thermocouple inside the sample container.

\subsection{Chemical Measurements (Environmental)}

The environmental temperature of the chamber must be recorded continuously or every 5 minutes during the 30 minute exposure to insure that it does not exceed $35^{\circ} \mathrm{C}$. The temperature sensor must be placed in the air at the level of the animals. A chromel-alumel thermocouple is recommended for this and has a sensitivity of approximately $40 \mathrm{uv} /$ deg. Celsius.

Continuous measurements for $\mathrm{O}_{2}, \mathrm{CO}_{2}$ and $\mathrm{CO}$ are to be made and recorded. Alternatively, if a gas chromatographic technique is used, measurements of $\mathrm{O}_{2}, \mathrm{CO}_{2}$ and $\mathrm{CO}$ are to be made every 3 to 5 minutes. The oxygen level in the chamber shall not fall below 188 any time during the exposure. Oxygen is to be supplied to the chamber to maintain the level between $18-21 \%$.

Continuous monitoring of $\mathrm{O}_{2}, \mathrm{CO}_{2}$ and $\mathrm{CO}$ will remove some of the products from the chamber. For example, approximately $0.5 \mathrm{liter} / \mathrm{min}$. flow rate is required for non-dispersive IR analysis of $\mathrm{CO}$ and $\mathrm{CO}_{2}$ and analysis of $0_{2}$. During a 30 minute exposure this amounts to 15 liters that must be pumped back into the chamber. Oxygen or air should be added depending on the degree of ${ }^{0}{ }_{2}$ depletion. One must correct for this addition when calculating the mass loading of combustion products.

The overall "concentration" of combustion products is based on mass loading of the sample into the furnace divided by the volume of the exposure chamber and is expressed in milligrams per liter or grams per cubic meter. It is this mass loading that is used to calculate the $L_{5} C_{50}$ i.e. the mass loading that results in the death of $1 / 2$ of the animal population. Equivalently, the $\mathrm{EC}_{50}$ is the mass loading $(\mathrm{mg} / \mathrm{l})$ that incapacitates $50 \%$ of the animal population in the 30 minute exposure period.

Measurement of other expected toxicants is optional. For example, HCl can be measured when vinil materials are being examined. Likewise, HCN can

$$
\text { A-4 }
$$


be measured as desired when nitrogen containing materials are thermally degraded.

\subsection{Biological Measurements}

During the exposure period, observations of the animal behavior should be noted and recorded. Time to loss of avoidance should be recorded. Any unusual behavioral activity should also be recorded along with the time.

Selected blood chemical measurements are required and measurement of other biochemical parameters is suggested. Measurements of $\mathrm{COHb}, \mathrm{O}_{2} \mathrm{Hb}$ and total $\mathrm{Hb}$ on at least 1 and preferably 2 animals at the time of incapacitation are required. If 2 of the 6 animals are not cannulated, 2 are to be removed at the time of incapacitation and blood samples obtained as rapidly as possible. The remaining 4 animals are to be exposed for the full 30 minutes unless they all die before the 30 minutes.

It is suggested that blood cyanide measurements be made when nitrogen containing polymers are being studied. This, however, is not required.

\section{DOSE RESPONSE EFFECTS}

Two end-points are to be obtained in the test procedure:

(1) incapacitation and

(2) death

Both of these experiments are to be determined as a function of the mass loading of combustion products. It is anticipated that both endpoints can be obtained during the same experiment although this is not always possible. That is, the time to incapacitation is recorded during the 30 minute exposure period, and the exposure is continued for the full 30 minutes even though the incapacitation occurred earlier.

The lethality endpoint is evaluated as a function of the mass loading in order to construct a dose-response curve from which the $\mathrm{LC}_{50}$ may be estimated. The $\mathrm{EC}_{50}$ may also be estimated by constructing a curve of the concentration versus percent-of-population-incapacitated in 30 minutes. The actual $\mathrm{LC}_{50}$ and $\mathrm{EC}_{50}$ with their $95 \%$ confidence limits should be obtained via an appropriate published statistical method, such as that of Litchfield and wilcoxon (7). In some cases, depending on the particular toxic products, incapacitation may not occur during the exposure period, but death may occur during the 14 days post exposure period. In these cases, it may not be possible to obtain an $\mathrm{EC}_{50}$ for that material.

The data for the lethality determination must include the deaths during the 30 minute exposure period and the 14 day post-exposure period.

Since an incapacitation model is used, a measurement of the time to incapacitation should be recorded, although the use of time to an effect is still open to discussion. The number of animals that die during the exposure and during the 14 days post-exposure period must be recorded.

\section{TEST PROCEDURE}

\subsection{Sample Preparation}

Material samples to be evaluated for toxicity should be conditioned in a constant humidity chamber maintained at 40 to $50 \%$ relative humidity at a room temperature of $22-24^{\circ} \mathrm{C}$ for a period of 48 hours prior to testing. The sample specimen is to be tested in one piece. 


\subsection{Combustion Conditions}

The toxicity of combustion products from any material is to be determined separately for non-flaming or smoldering combustion and for flaming combustion.

\subsubsection{Non-Flaming Conditions}

Each material is to be evaluated at 2 non-flaming temperatures: (1) $25^{\circ} \mathrm{C}$ below auto-ignition temperature with a maximum temperature of $800^{\circ} \mathrm{C}$ and (2) $440^{\circ} \mathrm{C}$, if $25^{\circ} \mathrm{C}$ below auto-ignition temperature is above $440^{\circ} \mathrm{C}$ by $50^{\circ} \mathrm{C}$ or more. The $440^{\circ} \mathrm{C}$ temperature is $25^{\circ} \mathrm{C}$ below the auto-ignition temperature of Douglas fir. The auto-ignition temperature will be different for each material and this temperature is to be established without animals as described below.

First, the temperature of the furnace is set at $500^{\circ} \mathrm{C}$ and when this temperature is attained, the material is introduced into the furnace. Sample size should be the maximum that one anticipates using for toxicity tests since a larger size may ignite at a lower temperature. Do not exceed $35 \mathrm{mg} / 1$ of mass loading (for 200 liter chamber this is a $7 \mathrm{gm}$ sample) to reduce risk of creating an explosive mixture. If auto-ignition does not occur, the process is repeated at $550^{\circ} \mathrm{C}$ and so forth until the auto-ignition temperature is bracketed within $25^{\circ} \mathrm{C}$ of the auto-ignition temperature. $800^{\circ} \mathrm{C}$ is the upper temperature at which the toxicity is to be studied regardless of whether auto-ignition occurs or not. If auto-ignition does occur at $500^{\circ} \mathrm{C}$, the furnace temperature should be decreased in increments until the auto-ignition temperature is bracketed within $25^{\circ} \mathrm{C}$.

Once the auto-ignition temperature of the material has been established, the furnace temperature is to be decreased by $25^{\circ} \mathrm{C}$ for the non-flaming condition. In other words, if a material auto-ignites at $450^{\circ} \mathrm{C}$, the maximum temperature at which this material is studied in the non-flaming mode of decomposition is $425^{\circ} \mathrm{C}$. The auto-ignition temperature may be sample size dependent, so that once this auto-ignition temperature is established with a given sample size, it should be checked without animals when the size is changed. However, for a given material only one temperature is used.

As a point of reference, Douglas fir has an auto-ignition temperature, established by the above procedure, of approximately $465^{\circ} \mathrm{C}$.

\subsubsection{Flaming Conditions}

The material must also be elevated under flaming conditions. The flaming mode of decomposition is to be carried out at a furnace temperature $25^{\circ} \mathrm{C}$ above the auto-ignition temperature established in the previous section. The $25^{\circ} \mathrm{C}$ increase in temperature is to insure ignition. In addition, $2-3$ drops of ethanol is to be added to the sample and an electric spark should be used to insure early ignition of the test material. It should also be noted that the maximum furnace temperature for flaming studies is $800^{\circ} \mathrm{C}$.

\subsection{Exposure Procedure}

Prior to experiments involving animal exposures, the system should be checked out to determine that the analytical and combustion systems are all operating correctly. The analytical instrumentation for $\mathrm{O}_{2}, \mathrm{CO}_{2}$ and $\mathrm{CO}$ should be calibrated with a known gas mixture containing the 3 gases. A regular calibration schedule of this instrumentation must be made. The $0_{2}$ can be checked with air.

To check the combustion system, the material to be tested for toxicity, including the reference material, should be used in the system before animals is involved. This check-out procedure is to determine: 
(1) the degree of oxygen depletion during combustion of the sample,

(2) the increase in temperature in the chamber during sample degradation and

(3) that the proper conditions have been established for carrying out either non-flaming or flaming combustion exclusively.

Once these conditions have been established, an experiment involving animals can be initiated.

The instrumentation for $\mathrm{CO}_{2}$ and $\mathrm{CO}$ measurements are zeroed and a base line established during the checkout procedure. Oxygen concentration is also recorded prior to initiation of the exposure.

The furnace temperature is established and the system allowed to reach equilibrium 10 minutes before the start of the experiment. During this warmup period and the recording of pre-exposure data, the door of the exposure chamber is left open.

After these conditions are established, the animals are placed in their respective positions. To initiate the experiment, the weighed sample is placed in the furnace, and the door of the chamber is immediately closed. Placement of the sample into the furnace designates the starting time of the exposure.

If temperature rise in the exposure chamber is a problem, the electrical power to the furnace may be cut off when the sample is completely degraded (3-5 minutes). The length of time required to degrade the sample can be determined by watching the increase of $\mathrm{CO}$ or $\mathrm{CO}_{2}$ concentrations. When these concentrations reach a steady state, the heater can be shut off.

If no animals are cannulated, two animals are to be removed at the time of incapacitation and the time recorded. Blood samples are to be obtained from these 2 animals as rapidly as possible. The remaining 4 animals are to be exposed for the full 30 minutes. If 2 animals are cannulated, the blood can be obtained at the time of incapacitation. These 2 animals should continue to be exposed for the full 30 minutes. If no incapacitation occurs, the exposure is to be terminated at 30 minutes.

The pathological examination on any animals that die during the exposure or are sacrificed immediately after the termination of the exposure should focus on the condition of the respiratory tract. Visual observations of soot deposits, pulmonary edema, hemorrhagic lungs, etc., should be recorded.

Clinical examination of post-exposure behavior of animals not killed during the exposure can be made, however this is optional. This examination, immediately after exposure, should include the following behavioral parameters: (1) exploratory behavior, (2) righting reflex, (3) pain reflex, (4) nuzzle reflex, (5) posture, (6) eye irritation, (7) nasal discharge, (8) respiratory irregularities (gasping, wheezing, etc.) (Irwin [8]). Any other unusual behavior patterns must be recorded.

The animals are to be kept for a period of 14 days post-exposure. Any deaths during this time period should be included in the lethality calculations. In addition, during these 14 days any unusual behavior should be noted and recorded including daily animal weights. 


\section{REPORTING OF DATA}

Required exposure chamber measurements are:

(1) carbon monoxide concentrations,

(2) carbon dioxide concentrations,

(3) oxygen concentrations, and

(4) temperature in the vicinity of the nose of the rats.

The above measurements are to be recorded at a minimum of 5 minute increments during the exposure.

The temperature at which the sample is thermally degraded must also be recorded.

Required biological measurements are:

(1) carboxyhemoglobin at time of incapacitation on

2 rats,

(2) total hemoglobin at time of incapacitation on

2 rats,

(3) oxyhemoglobin at time of incapacitation on 2 rats,

(4) time to incapacitation on all 6 rats, if incapacitation occurs, and

(5) mortality data during the exposure period and for the 14 day post-exposure period.

The blood chemistry measurements are to be done at the time of incapacitation or, if incapacitation does not occur, immediately after the 30 minute exposure.

In addition to the above required data, other observations can be made and recorded during and after exposure. For example, observations on animal posture, righting reflex, exploratory behavior, respiratory function (gasping, wheezing), grooming and eye and nasal discharge and body weight change should be recorded. This information will be useful in evaluating the extent of the toxicological insult.

\section{NUMBER OF EXPERIMENTS AND DATA REDUCTION}

As noted above, 6 animals are to be exposed per experiment. Dose response data based on lethality is to be obtained on each of 3 thermal degradation conditions. A minimum of 3 concentrations are required for each of these thermal conditions. The 3 thermal conditions are:

2 non-flaming conditions -

(1) $25^{\circ} \mathrm{C}$ below auto ignition temperature and

(2) at $440^{\circ} \mathrm{C}$ if condition (1) above is $490^{\circ} \mathrm{C}$ or greater

1 flaming condition -

(3) $25^{\circ} \mathrm{C}$ above auto ignition temperature

The minimum number of animals required to evaluate a given material is as follows:

3 (thermal conditions) $\times 6$ (animals/exp.) x 3 (concentrations minimum) $=54$ animals. 
It is unlikely that one can get a statistically valid $\mathrm{LC}_{50}$ based on 3 concentrations unless one can get about a $20 \%, 50 \%$ and $80 \%$ response on these 3 concentrations, so that it may require significantly more animals per material. The number of animals will also depend on the number of temperatures required to complete the evaluation.

Time to incapacitation, blood carboxyhemoglobin and the mortality data for each exposure should be recorded. The percent mortality for each concentration for a given thermal condition should be plotted, i.e., \& mortality should be plotted against mass loading of combustion products so that an $\mathrm{LC}_{50}$ can be estimated from the plot. This percent mortality must include all mortalities that occur during the exposure and the 14 day post exposure period. 
[1] MacFarland, H. N., "Respiratory Toxicology," Chapter 5 from Essays in Toxicology. Edited by W. Hayes, Jr., Acad. Press 1977.

[2] Guide for the Care and Use of Laboratory Animals, DHEW Publications No. (NIH) 74-23 (1974).

[3] Packham, S. C., "Behavior and Physiology: Tools for the Assessment of Relative Toxicity," Paper presented at 17 th National Cellular Plastics Conference on Safety and Product Liability, Washington, D.C. (Nov. 18$20,1974)$.

[4] Crane, Charles R., Sanders, Donald C., Endecott, Boyd, R., Abbott, John K., Smith, Paul W., "Inhalation Toxicology: I - Design of a Small Animal Test System, II - Determination of the Relative Toxic Hazards of 75 Aircraft Cabin Materials," FAA-AM-77-9, March 1977.

[5] Hartung, R., Ball, G. L., Boettner, E. A., Rosenbaum, R., Hollingsworth, Z. R., "Evaluation of the Performance of Rats Exposed to Combustion Products of Polyurethane Foams and Wood on a Roto Rod." To be published in November issue of Journal of Combustion Toxicity, 1977.

[6] Potts, W. J. and Lederer, T. S., "A Method for Comparative Testing of Smoke Toxicity," Journal of Combustion Toxicity, Vol. 4, pp. 114-162 (May 1977).

[7] Litchfield, J. T., Jr. and Wilcoxon, F., "A Simplified Method of Evaluating Dose-Effect Experiments," J. Pharmacol. and Exp. Therapeut. 96, 99-113 (1949).

[8] Irwin, S., Psychopharmacologia. Vol. 13, pp. 222-257, 1971. 


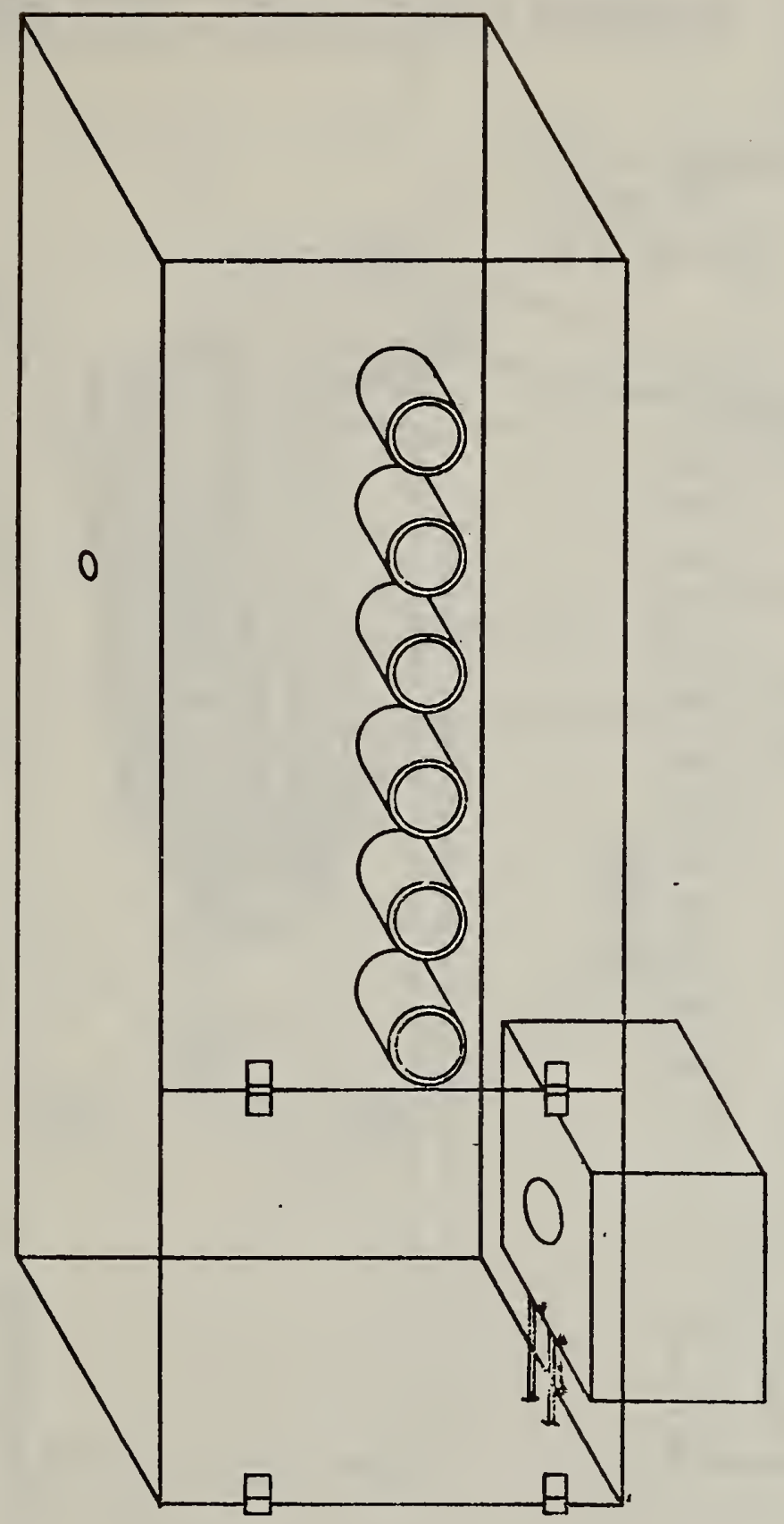

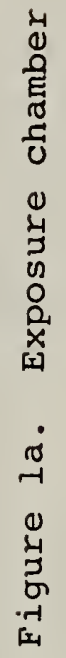



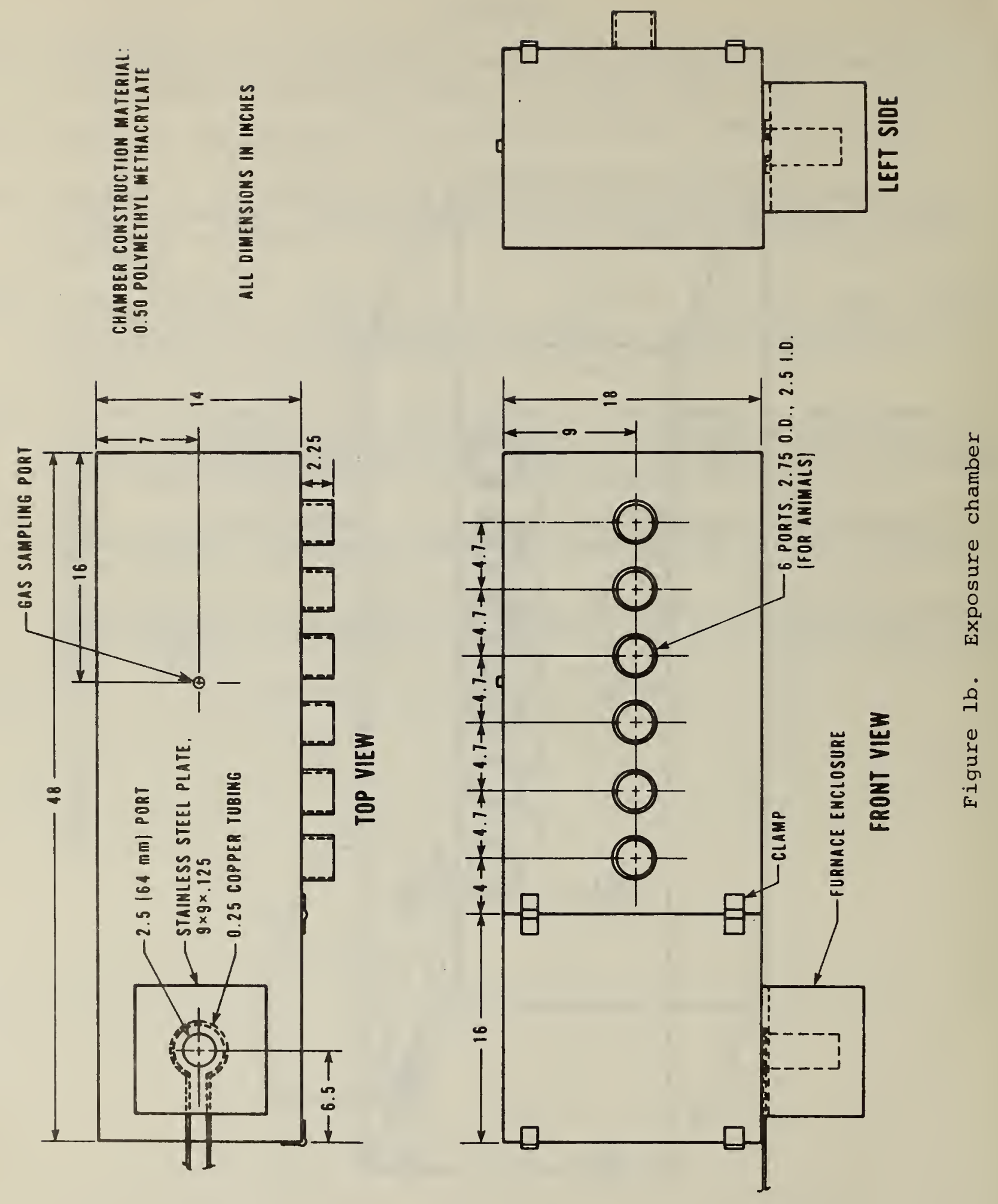


\section{PYROLYSIS/COMBUSTION FURNACE}

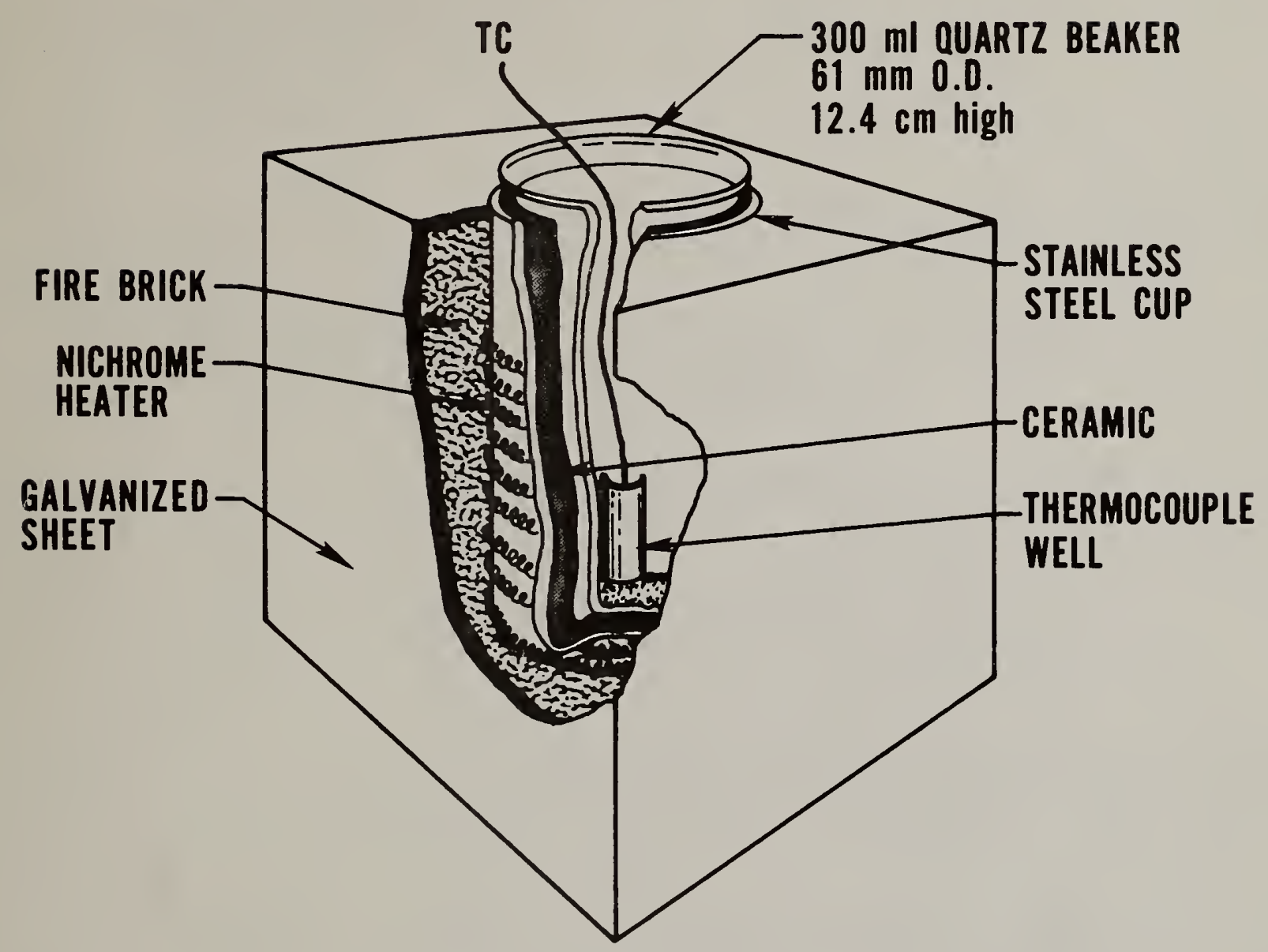

Figure 2. Cutaway drawing of the pyrolysis/combustion furnace. 
ABS. 11 4A IREV. 0.78

\begin{tabular}{|c|c|}
\hline $\begin{array}{c}\text { U.S. DEPT. OF COMM. } \\
\text { 8IBLIOGRAPHIC DATA } \\
\text { SHEET }\end{array}$ & $\begin{array}{c}\text { 1. PUBLICATION OR REPORT NO. } \\
\text { NBSIR } 80-2077\end{array}$ \\
\hline
\end{tabular}

4. TITLE AND SUBTITLE

Development of Recommended Test Method for Toxicological

Assessment of Inhaled Combustion Products

7. AUTHOR(S) Merritt li. Birky, Maya Paabo, Barbara C. Levin, Susan E. Womble, Dolores Malek

9. PERFORMING ORGANIZATION NAME AND ADDRESS

NATIONAL BUREAU OF STANDARDS

DEPARTMENT OF COMMERCE

WASHINGTON, DC 20234

12. SPONSQRNEG ORGANIZATION NAME AND COMPLETE ADDRESS (Streot, city, stato, zIP)

Prodicts Research Committee (PRC)

c/o Dr. John Lyons

National Bureau of Standards

Washington, D.C. 20234

15. SUPPLEMENTARY NOTES

Document describes a computer program; SF-185, FIPS Software Summary, is attached.

16. ABSTRACT (A 200-word or less factual summary of most significant information. If document includes a significant bibliography or literature survey, mention ithere.) The objective of the project supported by PRC was to develop a test method for measuring the toxicity of combustion products from polymeric materials including cellular plastics. The development of such a test procedure was considered an essential first step to determine the hazard to life when cellular plastics are involved in fire.

As a result of this work, a test procedure was developed. It consists of 3 major elements; (1) combustion system, (2) chemical analysis system and ( 3 ) animal exposure system. Two biological endpoints obtafned from the exposure are: (1) incapacitation in 30 minute exposure period, and (2) lethality in 30 minutes plus 14 days post exposure

The test apparatus has been evaluated to determine mixing rates and loss of reactive chemicals $i$ il the exposure chamber. In addition, a statistical evaluation of the experimental results demonstrated that order of incapacitation was independent of anima1 location.

Evaluation of a limited number of different materials that produce different toxicolog cal syndromes has demonstrated the utility of all 3 endpoints. Two natural polymers (wood and wool) and 2 synthetic materials (modacrylic and PTFE) have been studied indetail. In addition, preliminary data have been obtained on a flexible polyurethane ion $($ CM-21)

17. KEY WORDS (six to twelve entries; alphabetical order; capitalize only the first letter of the first key word unlose a proper namo; separated by emicolons) Combustion; fatality $\left(\mathrm{I}_{50}\right)$; hydrogen cyanide; incapacitation;

inhalation; test method; toxicology.
18. AVAILABILITY

For Official Distribution. Do flot Release to NTIS

Order From Sup. of Doc., U.S. Government Printing Office, Washington, DC 20402, SD Stock No. SNOO3-003-

K Order From National Technical Information Service (NTIS), Springfield,

VA. 22161

$$
\text { Xunlimited }
$$

\begin{tabular}{|l|c|}
\hline $\begin{array}{l}\text { 19. SECURITY CLASS } \\
\text { (THIS REPORT) }\end{array}$ & $\begin{array}{c}\text { 21. NO. OF } \\
\text { PRINTED PAGES } \\
63\end{array}$ \\
UNCLASSIFIED & $\begin{array}{r}\$ 7.00 \\
\text { 20. SECURITY CLASS } \\
\text { (THIS PAGE) }\end{array}$ \\
UNCLASSIFIED & USCOMM-DC \\
\hline
\end{tabular}



